\title{
Review \\ Electrochemical Methods and (Bio) Sensors for Rosmarinic Acid Investigation
}

\author{
Iulia Gabriela David *(D), Dana Elena Popa, Mihaela Buleandră and Mihaela Carmen Cheregi \\ Department of Analytical Chemistry, Faculty of Chemistry, University of Bucharest, Panduri Av. 90-92, District 5, \\ 050663 Bucharest, Romania; elena.popa@chimie.unibuc.ro (D.E.P.); mihaela.buleandra@g.unibuc.ro (M.B.); \\ mihaela.cheregi@g.unibuc.ro (M.C.C.) \\ * Correspondence: gabrielaiulia.david@g.unibuc.ro
}

Received: 23 June 2020; Accepted: 20 August 2020; Published: 22 August 2020

\begin{abstract}
Rosmarinic acid (RA) is an important bioactive phenolic acid with significant biochemical activities, including the antioxidant one. It is widely found in plants of the families Lamiaceae and Boraginaceae and has many uses in the food, pharmaceutical and cosmetics industries. RA is an electroactive species owing to the presence of the two catechol groups in its structure. Due to their inherent characteristics, such as sensitivity, selectivity, ease of operation and not too high costs, electrochemical methods of analysis are interesting tools for the assessment of redox-active compounds. Moreover, there is a good correlation between the redox potential of the analyte and its capability to donate electrons and, consequently, its antioxidant activity. Therefore, this paper presents a detailed overview of the electrochemical (bio)sensors and methods, in both stationary and dynamic systems, applied for RA investigation under different aspects. These comprise its antioxidant activity, its interaction with biological important molecules and the quantification of RA or total polyphenolic content in different samples.
\end{abstract}

Keywords: rosmarinic acid; voltammetry; amperometry; electrodes; biosensors; antioxidant; electrochemical detection

\section{Introduction}

Polyphenolic compounds (PCs) comprise a variety of substances, from very simple to extremely complex ones, with approximately 8000 such compounds being known [1]. PCs are indispensable for biological processes in plants having also structural functions [2]. Due to the fact that they are widely found in plants, vegetables, fruits, food and certain beverages, PCs are an intrinsic part of the human alimentation $[1,3]$.

Flavonoids and phenolic acids are the main classes of polyphenols. They have many various biochemical actions, including the antioxidant one, which consists in the direct and indirect scavenging of free radicals either by stopping their generation by trapping them and finishing the undesirable reaction before the target molecule suffers permanent impairment [1] or through chelating metals, respectively. In other words, although representing a comprehensive concept, it can be briefly said that antioxidants hamper the oxidative deterioration [4]. The PCs antioxidant activity depends on the number and positions of the hydroxyl groups vs. the carboxyl ones and increases with the number of hydroxyl groups [5].

Owing to their inhibiting effects on the oxidative processes and on the growth of various pathogens (bacteria, viruses and fungi), natural polyphenols became an alternative of choice to chemical antioxidants and antimicrobials in the food industry [6], thus being useful for the maintenance of food nutritional quality [7]. It was also proven that PCs have an important role in averting diverse oxidative stress based chronic, neurodegenerative and cardiovascular diseases, in the prevention 
of cancer, osteoporosis and diabetes, but also in restricting atheroma evolution by the inhibition of low-density lipoprotein oxidation $[3,8]$. Besides, some reported studies demonstrated that PCs hinder the replication of HIV (human immunodeficiency virus), HSV (human simplex virus) and inhibit glucosyl transferases of Streptococcus mutans (responsible for dental caries) [2].

Phenolic acids are divided in (hydroxy) benzoic acids (C6-C1 carbon atoms structure) and (hydroxy)cinnamic acids (C6-C3, having 3 carbon atoms in the side chain), existing in free or conjugated forms [5]. Hydroxycinnamic acids (HCAs), namely rosmarinic acid, para-coumaric acid, caffeic acid, ferulic acid and synapic acid, have a phenylpropanoid structure, which consists of an aromatic ring bearing different substituents (most often hydroxyl or methoxy groups) and a propane residue that can also be substituted as it is the case of RA. These acids are found in cereals, oil seeds, tea leaves, coffee, red wine, fruits, vegetables and whole grains. Their efficiency as antioxidants is correlated with their structural features by scavenging hydroxyl, superoxide anion and peroxyl radicals, peroxinitrite and singlet oxygen, but also through metal chelation, chain interruption and enzymatic activity modulation $[9,10]$. For example, manifold varieties of Tamarillo (Solanum betaceum), a fruit with therapeutic and nutritional attributes, have in composition various classes of compounds, among which are phenolic acids, especially hydroxycinnamic acid derivatives, namely rosmarinic acid glucosides, their malonyl derivative, as well as and rosmarinic acid [11].

A significant representative of HCAs that presents a special interest due to its properties, effects and uses is rosmarinic acid (RA). RA, a naturally occurring antioxidant, is an ester of caffeic acid (CAFA) and 3,4-dihydroxyphenyl lactic acid (DHPLA) (Figure 1) [12]. It comprises two catechol moieties, thus having two pairs of ortho hydroxyl groups grafted on two phenolic rings [13], which can be easy oxidized, being thus responsible for RA electroactivity. It is well known that electroanalysis possess unique favorable features for the rapid, sensitive and selective investigation of redox-active compounds. Thus, considering the importance of this electroactive phenolic acid, it is essential to take advantage of the opportunities offered by the electroanalytical techniques for its assessment. To the best of our knowledge, to date, there is no comprehensive review of the electrochemical (bio)sensors and methods developed and applied for RA assessment. Therefore, after a brief report of RA biological activities, this paper presents a detailed discussion of the static or dynamic voltammetric and amperometric methods at different electrodes employed for RA quantification as such or as total polyphenolic content (TPC) expressed as RA equivalent in different samples and for the investigation of its antioxidant activity and interactions with various molecules, for a better understanding of its action in biological systems.

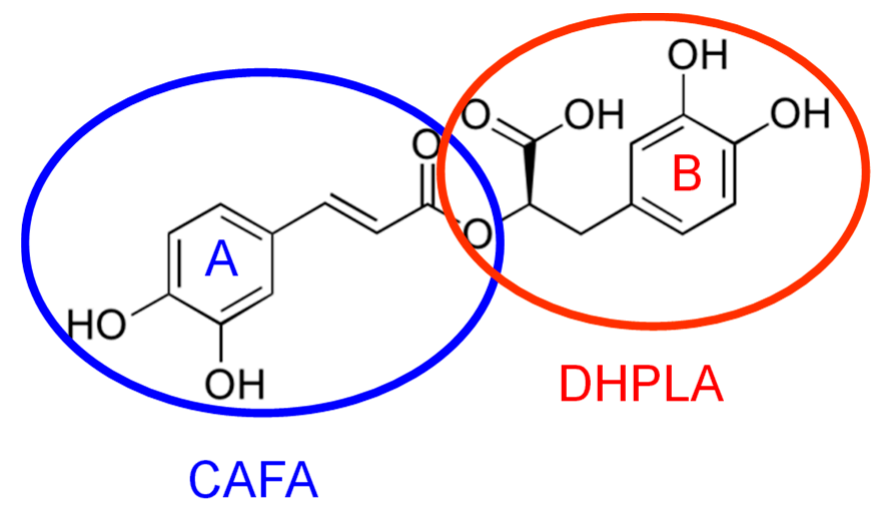

Figure 1. Rosmarinic acid (RA) chemical structure emphasizing the two electroactive catechol moieties.

\section{Rosmarinic Acid}

Although RA was separated for the first time from rosemary (Rosmarinus officinalis L.) in 1958 [14], its chemical synthesis was accomplished in 1991. From a structural point of view, RA contains an 
ester bond between an essential aromatic $\alpha$-aminoacid and a non-essential one, namely phenylalanine and tyrosine [15].

RA is present in many plants, herbs, spices, vegetables and fruits [16-19]. It exists in culinary and medicinal plants as a secondary metabolite [20]. Therefore, here are some important sources of RA: rosemary, mint, spearmint, lemon balm, perilla, salvia, basil, sage, marjoram, different species of thyme, oregano, savory, tamarillo [2,4,11,20-27]. Ferns, hornworts and sea grass must be also mentioned as sources of this polyphenolic compound [23]. It is worth emphasizing that RA is characteristic for thyme honey [28].

RA has multiple biological and pharmaceutical activities: antioxidant, anti-inflammatory, anti-mutagenic, antibacterial, anti-tumor, hepato-protective and anti-hepatitis, cardio-protective, antiviral, anti-carcinogenic, anti-convulsant, immunomodulatory, anti-metastatic, anti-angiogenic, astringent and anti-allergic [16,17,29-32]. It also helps the fertilization capacity increase [13] and the cognitive efficiency enhancement (neuroprotective activity) [19].

It must be outlined that it was reported that RA has an antioxidant activity three times higher than Trolox, thereby being established his powerful free radicals scavenging activity [30]. Moreover, when is intravenously administrated to mice, RA presents low toxicity and is quickly removed from the bloodstream [31].

Thanks to its multiple and significant characteristics, RA has various uses and applications: due to its antioxidant and astringent effects, RA is used in the cosmetics industry [16,29]; RA is applied for treatment of infections with Herpes simplex [30]; some pharmacological studies reported that RA helps in tissue damage precluding because it exhibits photo-protection, participating to UV and other ionizing radiations inhibition and transformation into milder radiation [17]; it helps dealing with autoimmune disorders, HIV and blood clots [31,33], but also with Alzheimer's disease [19] by preventing the formation of amyloid-B plaques in the brain, possibly responsible for this illness [14]; RA is also employed against amyotrophic lateral sclerosis, a prevalent neurodegenerative disease [14]; RA is used for food flavoring and preservation [19-21]; it supports atopic dermatitis treatment [22,33]; it proved to have anti-poisoning effects by the neutralization of snake venoms and fish toxins [22]; RA can be useful in treating allergic asthma, rheumatoid arthritis, peptic ulcers and cataract [23]; taking into consideration the neuroprotective effect and the metal-chelating properties, RA can participate in Parkinson's disease managing [34]; the demonstrated scavenging activity of RA for ONOO(responsible for neurological brain damage) has as outcome the fact that regular consumption of RA may protect against memory impairments [35].

The ingested rosemary infusion has digestive, diuretic, cardiotonic, antihypertensive, sedative, hepato-protective effects, being used as well against headaches and sea-sickness, whereas externally possesses different actions (nasal decongestive, vaginal antiseptic, anti-podalgic) [2].

Many herbs and spices were analyzed and high amounts of RA were found in sage, thyme and oregano, this being responsible, along with other phenolic compounds, for the antioxidant activity of these plants [36].

An unusual successful application of RA consisted in adding this compound in Russian sturgeon sperm during cryopreservation, RA assuring the sample protection against oxidative stress [37].

Another uncommon study comprised electrochemical tests applied in order to investigate the synergistic effect of the Lemon Balm leaves extract and $\mathrm{Zn}^{2+}$ ions mixtures for carbon steel corrosion mitigation in saline electrolyte [27]. Based on the polarization curves, a mixt inhibition mechanism was established, this being supported by the precipitation on the cathodic zone of zinc oxide/hydroxide and the deposition on the anodic zone of complexes formed between RA, chlorogenic acid (CGA) and luteolin (from the Lemon Balm), and ferrous and zinc cations.

The special antioxidant behavior of RA that underlies many of his properties was extensively studied, explaining the higher antioxidant potential of RA in comparison with several other HCA derivatives. The free radical scavenging activity is ensured by the RA structure, namely the four 
phenolic hydrogen atoms along with the catechol moieties, RA being able to enter into the lipid bilayers and defend these against oxidation $[10,21]$.

Various natural polyphenols contain compounds acting as electron-shuttles (ESs) (substances able to enhance the redox reactions rates, accelerating the electron transfer efficiency for electrochemical reactions), these being extremely useful in the metabolisms of the living organisms. It is well known that the amounts of ESs vary from plant to plant, but some species have plenty of ESs (such as RA or GCA). Thus, it was reported that Origanum majorana L. and Salvia officinalis L. species contain between $15 \%$ and $18 \%$ RA, respectively [38]. Therefore, RA, as an ES found in plants, has a crucial role in supporting life.

\section{Electroanalytical Investigation of RA}

\subsection{Why Electroanalysis?}

Electrochemical techniques (namely voltammetry and amperometry) involve the measurement of an electrical current generated by the analyte(s) charge transfer reactions taking place at the electrode-solution interface under controlled potential. Therefore, electroanalysis is widely used to investigate the redox behavior (mainly cyclic voltammetry- $\mathrm{CV}$ ) of various compounds, thus helping in identifying the redox mechanism of biological important species and providing information about the biological/pharmacological actions (e.g., antioxidant activity $[39,40]$ ) of the target analyte. Based on the direct dependence of the electrochemical signal on the analyte concentration, voltammetric (particularly differential pulse voltammetry-DPV and square wave voltammetry-SWV) and amperometric methods are also successfully applied to the sensitive quantitative determination of electrochemical active molecules. The intrinsic high sensitivity (based on the combination of various types of potential sweeps and steps in order to improve the signal to noise ratio by minimizing the nonfaradaic component of the current) $[9,41]$ and selectivity of these methods can be further improved by the proper selection of the applied potential and/or of the working electrode active surface, which can be modified with various compounds/materials (inorganic, organic, metal-organic, biological, composite and nanomaterials) $[13,31,42]$ that may interact specifically with the target analyte. It may be noteworthy to emphasize here that, due to their proven electrochemical important properties (e.g., large surface to volume ratio, enhanced charge transfer capabilities, etc.), in recent years, different types of nanomaterials, especially carbon nanotubes and various nanoparticles were even more employed to modify the electrodes surface, in order to improve the sensors and biosensors electrochemical responses and thus their performance characteristics.

In the actual context of antioxidants evaluation, which is often realized by spectrometric measurements in the visible range, electrochemical assays have the advantages that they can be applied also for the analysis in turbid and colored media, independent on the optical path length and they do not need addition of special reagents, as they are based on the physico-chemical properties (the redox behavior) of the analyte(s) [40].

Thus, electroanalytical techniques offer improved analytical performances with short analysis times, facile operation and not too high costs (low reagent consumption and instrumentation not as expensive as the spectrometric or chromatographic ones). Electrochemical methods are eco-friendly because: (i) they need a reduced number of reagents (mainly non-toxic supporting electrolytes, e.g., phosphate buffer [7,21,29-31,33], Mcllvaine buffer [8], acetate buffer solution [16,31], etc.) and small sample volumes (e.g., approximately $10 \mathrm{~mL}$ in conventional electrochemical cells [16,29-31], $1 \mathrm{~mL}$ using one compartment cells [17] or $\mu \mathrm{L} / \mathrm{few}$ drops when using screen printed electrodes-SPE [7,32]), generating thus insignificant waste amounts; (ii) many analytes (e.g., polyphenols and especially, in the present discussion, RA) are electroactive and they can be thus detected directly, without previous derivatization, and (iii) most often, even for mixtures or complex matrices, the sample preparation involves only basic operations, such as filtration (e.g., RA determination in Rosmarinus officinalis $L$. and Melissa officinalis herbs, where the samples were mixed with ultrapure water, heated at $50^{\circ} \mathrm{C}$, filtered 
and aliquots of the supernatant were voltammetrically analyzed without any dilution [13]), extraction (with water:ethanol mixtures from sage [8], from Prunella vulgaris using ethanol [33] and with methanol from spices [43]) and dilution, without the requirement of tedious, time and reagents consuming steps.

Miniaturization, portability (small accumulator based instruments) and single-use (e.g., SPE or the pencil graphite electrode-PGE) are other advantageous features of the electrochemical instrumentation.

On the other hand, electrochemical sensing can operate in stationary (batch) and in flow (dynamic) systems, coupled as detectors in various separation techniques [44]. Stationary systems are usually applied in the quantitative analysis of low analytes' concentrations and for studying the interactions between the analyte and various biological significant molecules, whereas dynamic systems are employed for the rapid and sensitive analysis of simple compounds [39].

PCs are characterized by an aromatic skeleton bearing one or more hydroxyl groups, which are responsible for their antioxidant and electrochemical activities [9,45], being thus adequate for electroanalysis by different voltammetric techniques using various working sensors and biosensors [46].

\subsection{Electrochemical Behavior of Rosmarinic Acid}

As it was already stated in the introduction, the RA molecule contains two oxidizable catechol moieties: ring $\mathrm{A}$, the CAFA, and ring $\mathrm{B}$, the DHPLA residues, respectively (Figure 1), which are independent of each other. These electroactive groups are responsible for the RA antioxidant activity and they also make possible RA analysis and quantification by electrochemical techniques.

The mechanism of HCAs antioxidant action was investigated by on-line monitoring of the UV-spectral changes in time occurring during their electrochemical (CV and controlled potential electrolysis) and chemical oxidation (with lead dioxide). The final solutions were analyzed by high-performance chromatography-mass spectrometry (HPLC-MS). Cyclic voltammograms recorded for HCAs, including RA, in anhydrous acetonitrile at a static glassy carbon electrode (GCE) were similar, all of them presenting a well-defined irreversible anodic peak and a broadened cathodic wave in the reverse scan. Anodic oxidation of mono- and di-HCAs involves a reversible two-electron process generating the corresponding stable phenoxonium cation, while the electron spin resonance spectroscopic results also indicated a cyclization product. The lower peak potential values of the di-HCAs oxidation signals were attributed to the electron donating effect of the unsaturated side-chain in para-position, whereas the small differences in these anodic potentials could be explained by possible secondary interactions (hydrogen bonds) between the different functional groups of the various analytes. In the presence of 2,6-lutidine as a deprotonating agent, the anodic peak increased and shifted towards less positive potentials, indicating an increase in the nucleophilicity of the antioxidant. Chemical oxidation of chlorogenic and rosmarinic acids and the ethyl ester of CAFA gave the corresponding neutral ortho-quinones [47].

The electrochemical response of structurally related polyphenolic antioxidants (among them being RA) was investigated by CV and electrochemical impedance spectroscopy on gold electrodes modified with different gold nanoparticles-chitosan (CS) nanocomposite films, depending on the carboxylic acid used for their fabrication, namely acetic, malonic and oxalic acids, respectively. The divers redox behavior of the tested antioxidants could be due to the differences in their chemical structures and, consequently, to different interactions with the electrode materials. In the case of RA, a shift of the oxidation potential towards less positive values and an increase in the anodic peak current were observed at all the modified Au electrodes in comparison with the bare electrode, suggesting that the nanocomposites provide higher electron-conductivities and a thermodynamically more favored antioxidant activity. On the other hand, the authors considered that electrostatic interactions between the amino groups in CS and the phenolic and/or carboxylic groups of the antioxidant could also enhance the interaction with gold and thus the electron transfer. Regarding the influence of the PCs chemical structure on their redox properties, the results emphasized that catechol, 4-tert-butylcatechol, CAFA and RA showed the best electrochemical performances in terms of current increase and potential shift. This may be due to the two hydroxyl groups in the ortho-positions, which could promote 
the interactions with the CS structure. The authors attributed the RA good electrochemical performance to its quasi-symmetric structure, which is more important than the steric hindrance [42].

The overall rate of an electrode process is affected not only by the electrode reaction itself, but also by the mass transfer of the analyte, i.e., RA, (mainly diffusion in voltammetric conditions due to the high concentration of the supporting electrolyte) from the bulk solution to the electroactive surface and also by other processes that may be involved, e.g., analyte adsorption. The different relationships between the redox peak currents and the scan rates obtained by CV constitute the diagnosis criteria for the evaluation of the effects due to both the reactant reaching the electrode via diffusion and its adsorption onto the electrode surface. Diffusion-limited electrode processes are characterized by a linear increase of the peak currents with the square root of the scan rate [48] according to the Equation (1):

$$
\mathrm{I}_{\mathrm{p}}=2.96 \times 10^{5} \mathrm{n}^{3 / 2} \mathrm{~A} \mathrm{D}^{1 / 2} \mathrm{Cv}^{1 / 2}
$$

where $I_{p}$ is the oxidation peak current $(A), n$ is the number of transferred electrons, $A$ is the electroactive surface area of the working electrode $\left(\mathrm{cm}^{2}\right), \mathrm{D}$ is the diffusion coefficient of the electroactive species $\left(\mathrm{cm}^{2} \times \mathrm{s}^{-1}\right), \mathrm{C}$ is the concentration of the redox species in the bulk solution $\left(\mathrm{mol} \times \mathrm{cm}^{-3}\right)$ and $\mathrm{v}$ is the potential scan rate $\left(\mathrm{V} \times \mathrm{s}^{-1}\right)$. Using Equation (1), the electroactive surface area of the working electrode, A, can be experimentally determined from cyclic voltammograms of $\mathrm{K}_{3} \mathrm{Fe}(\mathrm{CN})_{6}$ in a supporting electrolyte such as $\mathrm{KCl}$, whose diffusion coefficient is available in the literature. The analyte diffusion coefficient, $D$, can be determined from the slope of the linear $I_{p}=f\left(v^{1 / 2}\right)$ dependence, as was the case for RA oxidation at C-SPE, which will be detailed later [49].

A linear dependence of the peak currents on the potential scan rate indicates an electrochemical process controlled by the analyte adsorption on the electroactive surface of the working electrode, a phenomenon known as the surface process [33]. On the other hand, the nature of an electrode process can be established by taking into consideration the slope of the $\log \mathrm{I}_{\mathrm{p}} \mathrm{vs}$. $\log \mathrm{v}$ plot, which has the theoretical values of 0.5 for diffusion and 1.0 for adsorption-controlled processes, whereas an intermediate value indicates a complex adsorption-diffusion process within the electrochemical reactions of the analyte $[18,48,50]$.

Wang et al. [33] investigated for the first time the RA electrode reaction mechanism. Cyclic voltammograms recorded for RA at an electrochemical pretreated GCE in phosphate buffer solution (PBS) pH 7.40 revealed two pairs of well-defined redox couples situated at low positive potentials (anodic signals: $0.154 \mathrm{~V}$ and $0.224 \mathrm{~V}$; cathodic signals: $0.148 \mathrm{~V}$ and $0.220 \mathrm{~V}$ ). The signals were attributed to reversible redox surface processes involving the two pairs of phenol hydroxyl groups in ring A (the peaks pair situated at less positive potentials) and in ring B, respectively. From the potential-pH dependence of these peaks, it was concluded that the overall electrode process of RA involves four electrons and four protons (two protons and two electrons in each step). The RA coverage on the GCE was determined by chronocoulometry, whereas square wave stripping voltammetry (SWSV) was applied for RA quantitative determination (Table 1). Using CV, DPV and SWV at GCE in PBS pH 7.00, Gil et al. [17] confirmed these findings, emphasizing that the first anodic signal corresponds to the CAFA moiety oxidation, whereas the second anodic peak is due to the oxidation of the DHPLA residue. RA cyclic voltammograms recorded in Britton Robinson Buffer (BRB) solution (pH 1.80) at a GCE presented two pairs of signals (each corresponding also to a reversible two-electron electrode reaction), the first oxidation signal appearing as a shoulder at $0.486 \mathrm{~V}$, whereas the second was a well-defined peak situated at $0.535 \mathrm{~V}$ [12]. 
Table 1. Sensors and the performance characteristics of electrochemical methods presented in the literature for RA and/or TPC quantification.

\begin{tabular}{|c|c|c|c|c|c|}
\hline Sensor & Technique/Potential (V) * & Linear Range (M) & LOD (M) & Sample & Ref \\
\hline GCE & $\mathrm{CV}$ & $4.95 \times 10^{-5}-4.95 \times 10^{-4}$ & $1.20 \times 10^{-6}$ & Spices extracts & [43] \\
\hline GCE & SWSV & $3.00 \times 10^{-9}-1.50 \times 10^{-6}$ & $1.80 \times 10^{-9}$ & Prunella vulgaris & [33] \\
\hline PGE & DPV & $1.00 \times 10^{-8}-1.00 \times 10^{-5}$ & $7.93 \times 10^{-9}$ & Tea infusion/TPC & [19] \\
\hline CS-CNTPE/DNA & SWSV & $4.00 \times 10^{-8}-1.50 \times 10^{-6}$ & $1.40 \times 10^{-8}$ & Rosemary extract & [31] \\
\hline GCE/PoPD/Pt & $\mathrm{CA} /(0.065) \mathrm{DPV}$ & $\begin{array}{l}1.00 \times 10^{-6}-5.50 \times 10^{-5} \\
2.00 \times 10^{-6}-1.00 \times 10^{-5}\end{array}$ & $\begin{array}{l}5.00 \times 10^{-7} \\
7.00 \times 10^{-7}\end{array}$ & $\begin{array}{c}\text { Melissa officinallis, } \\
\text { Rosmarinus officinalis }\end{array}$ & [13] \\
\hline CPE/Fe(III)Zn(II) & SWV & $2.98 \times 10^{-5}-3.83 \times 10^{-4}$ & $2.30 \times 10^{-6}$ & Melissa officinalis extracts & [30] \\
\hline CPE/RA-silica & TLC-DPV & $6.94 \times 10^{-5}-9.53 \times 10^{-3}$ & $1.20 \times 10^{-5}$ & Rosemary extract & [51] \\
\hline CPE/Per-BMI-Tf2N-CS & SWV & $9.07 \times 10^{-7}-4.46 \times 10^{-6}$ & $7.25 \times 10^{-8}$ & Plant extracts & [52] \\
\hline $\mathrm{CPE} / \mathrm{Per}-\mathrm{Au}-\mathrm{BMI} \cdot \mathrm{PF}_{6}-\mathrm{CTN}$ & SWV & $5.00 \times 10^{-7}-2.37 \times 10^{-5}$ & $7.01 \times 10^{-8}$ & Pharmaceutical samples & [29] \\
\hline CPE/Lacc-BMI-PF 6 & SWV & $9.99 \times 10^{-7}-6.54 \times 10^{-5}$ & $1.88 \times 10^{-7}$ & Melissa officinalis extracts & [16] \\
\hline $\mathrm{Au}-\mathrm{SPE} / \mathrm{Lacc}-\mathrm{Naf}$ & $\mathrm{CA} /(-0.200)$ & $3.00 \times 10^{-6}-1.50 \times 10^{-5}$ & $2.4 \times 10^{-6}$ & & \\
\hline C-SPE/Lacc-Naf & $\mathrm{CA} /(-0.030)$ & $7.00 \times 10^{-7}-1.50 \times 10^{-6}$ & $1.19 \times 10^{-7}$ & Sage extracts/TPC & [7] \\
\hline C-SPE/Lacc-Naf & $\mathrm{CA} /(-0.030)$ & $1.00 \times 10^{-6}-1.00 \times 10^{-5}$ & $7.50 \times 10^{-7}$ & Sage extracts/TPC & [32] \\
\hline C-SPE/Pt-NPs-RGO-Lacc-Naf & $\mathrm{CA} /(-0.100)$ & $4.50 \times 10^{-7}-2.5 \times 10^{-6}$ & $1.50 \times 10^{-7}$ & Tea infusion/TPC & [53] \\
\hline C-SPE/Lacc-TESBA-ITO-NPs & $\mathrm{CA} /(-0.010)$ & $1.06 \times 10^{-6}-1.50 \times 10^{-5}$ & $9.10 \times 10^{-7}$ & Propolis extracts/TPC & [54] \\
\hline $\mathrm{Au} / \mathrm{Lacc}-\mathrm{CS}-\mathrm{MWCNT}$ & $\mathrm{CA} /(-0.020)$ & $9.10 \times 10^{-7}-1.21 \times 10^{-5}$ & $2.33 \times 10^{-7}$ & $\begin{array}{l}\text { Salvia officinalis, Mentha } \\
\text { piperita extracts/TPC }\end{array}$ & [8] \\
\hline ITO/Lacc-Tyr-CS-MWCNT & $\mathrm{CA} /(-0.050)+$ surfactant Tween 20 & $4.00 \times 10^{-7}-1.20 \times 10^{-5}$ & $4.20 \times 10^{-8}$ & $\begin{array}{l}\text { Salvia, basillicum } \\
\text { extracts/TPC }\end{array}$ & [55] \\
\hline Graphite/Lacc-PDA & $\mathrm{CA} /(0.000 \mathrm{~V}$ vs. SCE $)$ & $1.00 \times 10^{-6}-2.00 \times 10^{-5}$ & $9.00 \times 10^{-8}$ & $\begin{array}{l}\text { Chestnut shell waste } \\
\text { extract/TPC }\end{array}$ & [56] \\
\hline
\end{tabular}

* vs. $\mathrm{Ag} / \mathrm{AgCl}$; LOD: limit of detection; GCE: glassy carbon electrode; CV: cyclic voltammetry; SWSV: square wave stripping voltammetry; PGE: pencil graphite electrode; DPV: differential pulse voltammetry; TPC: total polyphenolic content; CS-CNTPE/DNA: chitosan-modified carbon nanotube paste electrode covered with DNA; GCE/PoPD/Pt: Pt nanoparticles poly(ortho-phenylenediamine) film electrochemically modified glassy carbon electrode; CA: chronoamperometry; $\mathrm{CPE} / \mathrm{Fe}(\mathrm{III}) \mathrm{Zn}(\mathrm{II})$ : carbon paste electrode modified with a biomimetic $\mathrm{Fe}(\mathrm{III}) \mathrm{Zn}$ (II) complex; CPE/RA-silica: rosmarinic acid-silica carbon paste electrode; TLC-DPV; thin-layer chromatography-differential pulse voltammetry in solid state; CPE/Per-BMI-Tf2N-CS: peroxidase (from pine nuts of Araucaria angustifolia) 1-butyl-3-methylimidazolium bis(trifluoromethylsulfonyl)imide ionic liquid chitosan carbon paste electrode; $\mathrm{CPE} / \mathrm{Per}-\mathrm{Au}-\mathrm{BMI} \mathrm{PF}_{6}-\mathrm{CTN}$ : peroxidase (from homogenate of pea (Pisum sativum)) gold nanoparticles and 1-butyl-3-methylimidazolium hexafluorophosphate ionic liquid supported in chitin carbon paste electrode; CPE/Lacc-BMI $\mathrm{PF}_{6}$ : laccase 1-n-butyl-3-methylimidazolium hexafluorophosphate carbon paste electrode; Au-SPE/Lacc-Naf: laccase Nafion modified gold screen printed electrode; C-SPE/Lacc-Naf: laccase Nafion modified carbon screen printed electrode; C-SPE/Pt-NPs-RGO-Lacc-Naf: laccase-platinum nanoparticles-reduced graphene oxide-Nafion modified carbon screen-printed electrode; C-SPE/Lacc-TESBA-ITO-NPs: laccase trihydroxisylilbutyraldehyde indium tin oxide nanoparticles modified carbon screen printed electrode; Au/Lacc-CS-MWCNT: laccase-multiwall carbon nanotubes-chitosan modified gold foil; ITO/Lacc-Tyr-CS-MWCNT: laccase-tyrosinase-multiwall carbon nanotubes-chitosan modified indium tin oxide electrode; Graphite/Lacc-PDA: graphite laccase polydopamine electrode; SCE: saturated calomel electrode.

Experimental (CV, linear sweep voltammetry and DPV at GCE) and theoretical studies realized by Beiginejad et al. [18] on RA oxidation in aqueous solutions showed two two-electron oxidation-reduction peaks $\left(E_{\mathrm{r}} E_{\mathrm{r}}\right.$ mechanism), the electrode process being both diffusion and adsorption controlled as it was indicated by the $\log \mathrm{I}_{\mathrm{p}}=\mathrm{f}(\log \mathrm{v})$ graph slope value of 0.7 . In contrast to the data previously reported by Wang et al. [33] and Gil et al. [17], which were mentioned above, the results of Beiginejad's group showed that RA electrooxidation occurs first at ring B (DHPLA residue) and subsequently at ring A (CAFA moiety). On the other hand, the authors claimed that, in basic media, the electron transfer process is followed by a dimerization reaction. The $\mathrm{RA} \mathrm{pK}_{\mathrm{a}}$ of $3.62 \pm 0.02$ was also determined experimentally using electrochemical titration methods based on conductometry and potentiometry ( $\mathrm{pH}$-metry).

The electrochemical behavior and thus the mechanism of the charge transfer reaction (oxidation and/or reduction) and the whole electrode process of an analyte is strongly dependent on the electrode material, on the nature and $\mathrm{pH}$ of the supporting electrolyte as well as on the used instrumental parameters (e.g., scan rate in CV). As can be observed from the above-mentioned information that was found in the literature, RA electrochemistry usually relies on two quasi-reversible two-electron processes $[12,17,18,33]$. Nevertheless, based on the obtained peak potential difference of $20 \mathrm{mV}$, Peng et al. [21] considered RA oxidation at GCE in PBS ( $\mathrm{pH}$ 7.40) a quasi-reversible diffusion-controlled electrode process involving three electrons. CV studies in $0.1 \mathrm{M} \mathrm{H}_{2} \mathrm{SO}_{4}$ emphasized that RA signals observed at the disposable PGE are better shaped and higher in comparison to those recorded at the GCE and Pt electrode. RA electrooxidation at PGE [57] was also quasi-reversible and controlled by the analyte diffusion towards the electrode, but the number of changed electrons was found to be 
two. This outcome can be explained considering that: (i) (poly)phenols oxidation mechanisms are very complex and, depending on the experimental conditions, may involve more steps occurring at various rates, implying a different number of electrons and protons [42] and generating diverse intermediates (e.g., $o$-semiquinone radicals, which may further participate in reactions such as coupling, nucleophilic attack or proton loss) $[9,12,44,58-60]$ and (ii) PGE has a distinct structure compared to other carbon working electrodes, namely GCE, and thus it is possible for RA to interact in another manner with this graphite nanocomposite electrode material; the electrode processes occur differently and therefore only one two-electron redox process is observed. A reason for the observation of a single RA oxidation signal in acidic aqueous solution could be the formation of a thin film of RA at the electrode surface, thereby hindering the appearance of two anodic peaks, as is the case in neutral or more basic media, when RA solubility and adsorption decrease [18]. Using the same electrolyte, PGE was further used for RA quantitative analysis and the determination of the TPC in tea infusions (Table 1) [19].

In PBS (pH 7.00), at a carbon screen-printed electrode (C-SPE), RA was also oxidized in two diffusion controlled steps, as the $\mathrm{CV}$ showed in the anodic scan a shoulder at the potential of $0.085 \mathrm{~V}$ and a well-defined peak at $0.150 \mathrm{~V}$, accompanied in the reverse scan by the corresponding reduction steps occurring at $0.050 \mathrm{~V}$ (shoulder) and $0.120 \mathrm{~V}$ (well-shaped peak), respectively. At C-SPE, the RA redox peaks appeared at lower potentials when compared to GCE (as reported by Wang et al. [33]). The transfer coefficient $(\alpha)$, diffusion coefficient $(\mathrm{D})$ and the formal potentials $\left(\mathrm{E}^{\circ \prime}\right)$ of $\mathrm{RA}$ redox couples in PBS ( $\mathrm{pH} 7.00$ ) at C-SPE were found to be $0.283,9.07 \times 10^{-5} \mathrm{~cm}^{2} \mathrm{~s}^{-1}, 0.068 \mathrm{~V}\left(\mathrm{E}_{1}{ }^{\circ \prime}\right.$ ) for the first step and $0.135 \mathrm{~V}\left(\mathrm{E}_{2}{ }^{\circ \prime}\right)$ for the second step, respectively. Repetitive potential cycling resulted in RA electrodeposition on C-SPE, the CVs presenting well-defined anodic and cathodic peaks, typical for the RA quinone-hydroquinone redox couple. The authors considered that RA deposition onto the C-SPE was due to the formation of bonds between the quinone groups generated on the RA molecule structure during the electrooxidation process and the active groups formed at the C-SPE surface during its electrochemical pretreatment. Thus, RA was used as redox modifier of C-SPE in the construction of a C-SPE/RA sensor for the cofactor nicotinamide adenine dinucleotide (NADH) and a C-SPE/RA/ADH/GA biosensor for ethanol, obtained by the immobilization of alcohol dehydrogenase $(\mathrm{ADH})$ in the presence of glutaraldehyde (GA), respectively [49].

At a bare carbon paste electrode (CPE), RA showed a broad oxidation peak, whereas the signal became higher and better defined at the CS-modified carbon nanotube paste electrode (CS-CNTPE), fact attributed to the catalytic activity of both CS and carbon nanotubes (CNTs). On the other hand, the CS-CNTPE covered with DNA (CS-CNTPE/DNA) was able to distinguish the two steps of RA oxidation (similar to the mechanism proposed by Wang et al. [33]) generating a well-defined split anodic peak with an enhanced intensity due to the accumulation of RA on CS-CNTPE/DNA as a result of the strong interaction between RA and the immobilized DNA. This feature was further used for the sensitive quantification of RA (Table 1) [31].

DPV recorded for RA at bare GCE showed poor signals, but at the GCE modified with poly (o-phenylenediamine) and $\mathrm{Pt}$ nanoparticles (GCE/PoPD/Pt) the currents were 12 times higher. The coating (polymeric films and/or nanoparticles) thickness influences the analyte response as it was the case of RA at GCE/PoPD/Pt, where an excessive increase in the modifier layer inhibited the analyte transfer to the electrode surface. Fortunately, electrochemical techniques enable the control of coating thickness through an optimal selection of the working conditions (monomer/nanoparticles concentration, number of deposition/polymerization cycles, etc.) in order to enhance the performances compared with the ones of the bare electrode. CV studies on RA electrooxidation at GCE/PoPD/Pt suggested a quasi-reversible, $\mathrm{pH}$-dependent, adsorption controlled process that involves an equal number of electrons and protons [13].

Recently, electrochemistry was performed at a controlled potential (between 0.000 and $3.000 \mathrm{~V}$ ) in a three-electrode thin-layer flow-through electrochemical cell, having a porous GCE with large surface area $\left(14 \mathrm{~mm}^{2}\right)$ as a working electrode (to generate the analytes oxidation metabolites), coupled to online time-of-flight tandem mass spectrometry (EC/Q-TOF/MS) with the aim of investigating the oxidative 
transformation and metabolic pathway of phenolic acids, including RA, in samples of Danshen, used as a medicinal plant or/and functional food. In the first phase of oxidative metabolism simulation it was observed that RA oxidation starts at $0.400 \mathrm{~V}$ and the maximum yields of oxidation products were obtained at $0.700 \mathrm{~V}$. MS results led to the conclusion that, in these conditions, RA underwent a hydrolysis reaction of the ester bond generating DHPLA, followed by the loss of a water molecule and the formation of CAFA. During the phase II of the oxidative metabolism simulation, the electrochemical behavior of RA was investigated at applied voltages of 0.000 and $0.700 \mathrm{~V}$ in the presence of glutathione (GSH), which was used as a momentous trapping agent for the generated reactive products. MS data emphasized the formation of three GSH adducts (of RA, DHPLA and CAFA, respectively) [61].

\subsection{Electrochemical Quantitative Analysis of Rosmarinic Acid}

The electrochemical techniques mostly used, generally for polyphenols and especially for RA analysis, were amperometry for the quantitative determination and voltammetry (CV, DPV, SWV) for both the investigation of the electrochemical behavior of the analytes and their quantification. DPV and SWV may offer better selectivity [62] (e.g., the DPV simultaneous determination of RA and protocatechuic acid (PCA) at a GCE/PoPD/Pt [13]); however, as most often the analysis of polyphenols in real samples are not focused on the assessment of a given analyte, but on the evaluation of a group of compounds with similar properties (e.g., polyphenols), chronoamperometry is employed due to its enhanced sensitivity [62].

Different types of bare (mostly carbon based electrodes like GCE [33] and PGE [19]) or chemically modified electrodes with inorganic, organic materials, polymeric films, various nanomaterials, e.g., carbon nanotubes, nanoparticles, etc., or combinations of these, as well as biosensors have been developed and applied either to estimate the RA or the TPC of various samples (Table 1). A brief discussion of some of them will be presented below.

Biomimetic sensors gained more attention in recent years due to the need of the comprehension and the reproduction of the natural processes from the biological structures (nucleic acids, peptides, proteins, lipids, carbohydrates). There are different kinds of biomimetic sensors (e.g., chemical, electric, optical, acoustic, mechanical, etc.), and they were designed for various analytes/stimuli and applications. In the context of this review, these specific sensor types are bio-inspired devices (e.g., amperometric or potentiometric sensors) containing, as a recognition element, compounds or materials, such as metal complexes, conductive polymers, nanoparticles, etc. These mimic/imitate the activity/action (e.g., enzymatic) of a biological system designed to sensitive and selective detect and quantify a given analyte based on a specific signal (e.g., current, voltage, fluorescence intensity) generated by the presence of the target substance [63-65]. An example for such a type of transducers contains complexes of various metals that are able to mimic the active site(s) of different enzymes. The heterodinuclear Fe ${ }^{\mathrm{III}} \mathrm{Zn}^{\mathrm{II}}(\mu-\mathrm{OH})$ bpbpmp- $\left.\mathrm{CH}_{3}\right]\left(\mathrm{ClO}_{4}\right)_{2}$ complex, where the ligand $\mathrm{H}_{2}$ bpbpmp- $\mathrm{CH}_{3}$ is 2-[bis(2-pyridylmethyl)aminomethyl]-6-[(2-hydroxy-5-methylbenzyl)(2-pyridyl-methyl) aminomethyl]4-methyl-phenol, mimics the active site of purple acid phosphate isolated from plants. A CPE containing this biomimetic Fe(III) Zn(II) complex was developed and successfully applied for RA determination in plant extract samples (Table 1) [30].

An interesting approach for the preparation of a CPE using the thin-layer chromatographic spots of RA was developed by Gonçalves et al. for the DPV quantification of RA (Table 1) [51].

Biosensors represent a special type of electrochemical transducers that combine the specificity of the biological material as recognition element immobilized at the electrode surface with the capabilities of the electrode material and of the electrochemical techniques to generate a signal that is related to the analyte concentration.

Biosensors differ by the biological sensing material (e.g., enzymes, cells, antibodies, DNA chains, microorganism, etc.), the immobilization method (physical adsorption, covalent binding, cross-linking via bi-functional reagents, encapsulation and entrapment into a polymer matrix [66]) and the electrode material (carbon materials, gold, platinum, indium tin oxide (ITO) as such or modified) acting as support for the biological material immobilization and also as an electrochemical transducer 
generating the analytical signal used for the analyte quantification. The most used biosensors are the enzymatic ones.

Voltammetric/amperometric enzymatic biosensors have been widely applied to the polyphenolic antioxidants analysis due to several advantages offered, such as high selectivity, enhanced signals due to enzyme-catalyzed electrode reactions, and thus higher sensitivity, and the easy immobilization of the enzyme on the transducer. On the other hand, biosensors have short response times and they can be miniaturized and used in online analysis [62].

A major problem occurring during enzymatic biosensor application is related to the transducer surface passivation by the electropolymerization of the enzymatic products. Therefore, to protect the modified electrode from fouling, numerous enzymatic biosensors use Nafion coatings [55]. Conducting polymers were also used to improve the immobilization of the enzyme onto the electrode surface enhancing the robustness of the biosensor [62].

Enzymatic biosensors using redox enzymes (peroxidase, laccase and/or tyrosinase) as biorecognition element have been developed for the evaluation of PCs in different matrices, such as plant extracts, beverages or food samples [55].

The operational principle of the biosensors constructed for RA determination (Figure 2) is based on the enzyme-catalyzed oxidation of $\mathrm{RA}$ to its o-quinone derivative $\left(\mathrm{RA}_{\mathrm{ox}}\right)$, which is subsequently reduced back at the electrode surface to the initial phenolic compound $\left(\mathrm{RA}_{\mathrm{red}}\right)$, with the simultaneously recording of the electrochemical signal (reduction current), which is proportional to RA concentration, used afterwards for its quantification.

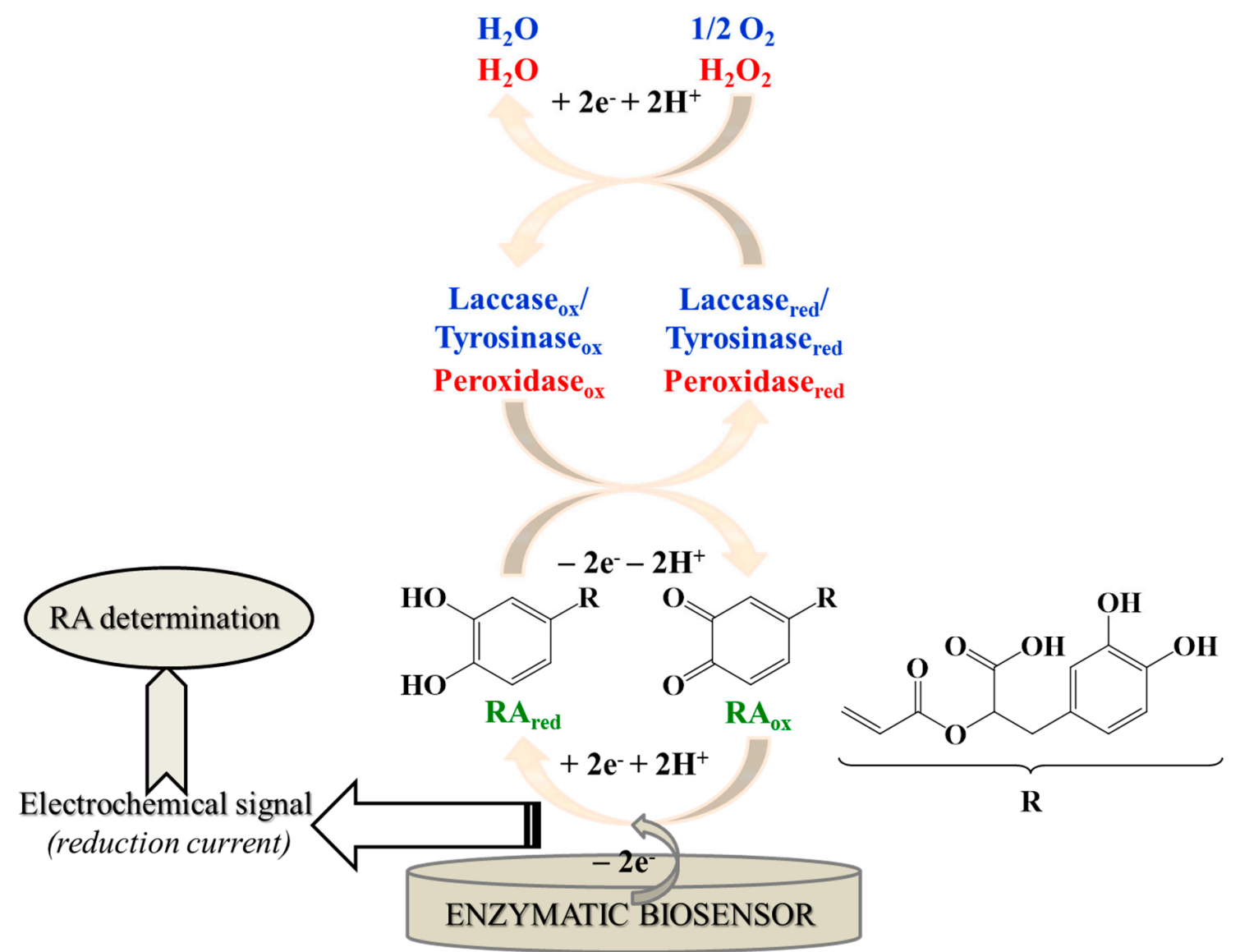

Figure 2. Operational principle for RA determination using enzymatic biosensors.

Peroxidases represent a class of enzymes found throughout nature, in higher plants, animals and microorganisms. Due to their stability and versatility, they are the most commonly employed 
enzymes in the fabrication of biosensors. Generally, peroxidases are heme proteins with iron (III) protoporphyrin IX as the prosthetic group. Peroxidases catalyze the oxidation of RA and also of other substrates, while hydrogen peroxide is reduced to water (Figure 2) [29,52].

Laccases are multicopper oxidases, also named "blue" copper oxidases, widely distributed in the nature (from bacterial species to fungi and plants [67]), that catalyze the oxidation of mono-, di-, poly-phenols (including RA), amino-phenols, methoxy-phenols, aromatic amines and ascorbate, through the four-electron reduction of molecular oxygen to water $[16,66,68]$. Similar to laccase, tyrosinase catalyzes, in the presence of oxygen, the oxidation of the $o$-phenols to the corresponding $o$-quinone [62].

Bare CPEs and biosensors based on laccase from Aspergillus oryzae and the ionic liquids 1-n-butyl-3-methylimidazolium hexafluorophosphate $\left(\mathrm{BMIPF}_{6}\right)$ or 1-n-butyl-3-methylimidazolium tetrafluoroborate $\left(\mathrm{BMIBF}_{4}\right)$ as binders were developed for the RA electrochemical investigation. The highest signal due to the RA o-quinone reduction was recorded at the $\mathrm{BMIPF}_{6}$-biosensor $\left(\mathrm{CPE} / \mathrm{Lacc}-\mathrm{BMIPF}_{6}\right)$. The authors considered that the better performance of this biosensor, in comparison to the laccase- $\mathrm{BMIBF}_{4}$ one, could be attributed to the fact that the $\mathrm{BMIPF}_{6}$ structure is hydrophobic, thus leading to a better stability (over 300 days without surface renewal), electrochemical conductivity and a wide electrode potential window of the biosensor, whereas the hydrophilic $\mathrm{BMIBF}_{4}$ structure leads to an unstable biosensor in aqueous solutions. The results obtained for the RA determination in plant extracts employing the CPE/Lacc-BMIPF 6 biosensor (Table 1) compared well with those achieved using a capillary electrophoresis method [16].

Gold (Au-SPE) or carbon (C-SPE) screen printed electrodes modified by drop casting with laccase from Trametes versicolor followed by immobilization in a Nafion membrane were developed and optimized for the determination of polyphenolic acids (RA, CAFA, CGA and gallic acid (GLA)) selected in agreement with LC-MS screening analysis performed for the investigated sage extracts. Due to its higher response sensitivity, the C-SPE laccase biosensor was applied for the evaluation of the TPC, expressed as the total rosmarinic acid equivalent (RAE), from plants cultivated in vitro [7]. This biosensor was further employed to monitor the accumulation of secondary polyphenolic metabolites of Salvia extracts, both from mother cells and synchronized cells, during in vitro growth of Salvia (maxima and verde) [32].

The analytical performance characteristics of a biosensor based on laccase-platinum nanoparticles (NPs)-reduced graphene oxide (RGO)-Nafion modified C-SPE (C-SPE/Pt-NPs-RGO-Lacc-Naf) were optimized using CAFA as substrate for the enzymatic reaction and it was applied to the determination of the TPC, expressed as molar equivalents of CAFA, from fruit tea infusions. Nevertheless, other polyphenols frequently found in fruit tea infusions, among them being RA, were also analyzed, and the analytical parameters for RA quantification are given in Table 1 [53].

ITO-NPs were modified with triethoxysilylbutyraldehyde (TESBA) to create carbonyl groups for the covalent immobilization of laccase. This nanocomposite was drop casted on a C-SPE and after the enzyme immobilization it was stabilized with a Nafion membrane. The performances of this amperometric biosensor were evaluated for RA, CAFA and catechol and it was applied to the assessment of the TPC of propolis extracts, expressed as caffeic acid equivalents (CAFAE) [54].

The TPCs, expressed as RAE, of plant extracts were evaluated using a laccase based sensor. The enzyme obtained from Trametes versicolor was immobilized on a gold surface by entrapment during the electrochemical deposition of a nanocomposite film of chitosan (CS) incorporating multiwall carbon nanotubes (MWCNT) [8]. A similar bienzymatic biosensor (ITO/Lacc-Tyr-CS-MWCNT), based on ITO electrode modified by co-entrapment of the enzymes laccase (from Trametes Versicolor) and tyrosinase (from mushrooms) into a CS-MWCNT matrix, exhibited a 10.7-fold increase in the response sensitivity and lower detection limits for RA. In the presence of the non-ionic surfactant Tween 20, the biosensor operational stability was improved and the linear concentration range was extended (up to $12 \mu \mathrm{M}$ for RA). The sensor was used to evaluate the TPC of plant extracts, expressed as RAE (Table 1) [55]. 
Cheap disposable graphite laccase-based electrochemical biosensors (graphite/Lacc-PDA) for polyphenol detection have been constructed using a one-step potentiostatic electropolymerization of dopamine (DA) for the robust enzyme immobilization on rectangular plates cut from a graphite rod. DA polymerization was carried out at $0.300 \mathrm{~V}$, in deaerated solutions to prevent the enzyme oxidation. The performance characteristics of graphite/Lacc-PDA biosensor were evaluated in oxygenated citrate-phosphate buffers solutions ( $\mathrm{pH}$ 4.60) using as standards GLA, CAFA and RA (Table 1). The sensor was applied to the chronoamperometric assay of low molecular phenols content in a chestnut shell's waste extract using the GLA calibration curve [56].

Selectivity is a critical issue of any analytical method used for the quantification of analytes with similar structures, as it is the case of polyphenolics, from complex matrices (plant extracts, food, biological fluids, etc.). For example, using the GCE in $0.1 \mathrm{M} \mathrm{LiClO}_{4}$ in ethanol, the individual antioxidants of spices were oxidized at very close positive potentials (e.g., RA (1.230 V), capsaicin $(1.200 \mathrm{~V})$, GLA $(0.880$ and $1.250 \mathrm{~V})$ and thymol $(1.290 \mathrm{~V}))$ [43]. Polyphenol oxidases commonly used as a recognition element in the construction of biosensors developed for voltammetric or amperometric analysis of RA are enzymes with group specificity and not with definite poly-phenol specificity, resulting in a lack of selective response to the desired analyte, offering instead the advantage of providing information on the TPC of the sample [7]. Thus, unfortunately, the electrochemical approaches employed for RA detection are not always very selective, but this drawback may be minimized by selecting the proper experimental conditions (e.g., using modified working electrodes $[13,16,30]$ or measuring at relatively low applied potentials $[7,8,54,59]$ (see Table 1$)$ ). Studies regarding the voltammetric behavior of RA and structurally related polyphenolic acids (e.g., CAFA, CGA, GLA) at PGE emphasized that these compounds are oxidized at almost the same potential so that their simultaneous individual detection is not possible by DPV, but it was shown that the current intensity of the RA anodic peak increased linearly with successive additions of the analyte to tea samples thus enabling the determination of the TPC of different tea sorts expressed as mg RAE/g dry tea [19]. On the other hand, Ozdocur et al. [13] reported that voltammetric recordings for a mixture of RA and PCA at GCE or GCE/Pt showed only one overlapped peak, whereas using a GCE/PoPD/Pt well separated DPV oxidation peaks $(0.100 \mathrm{~V}$ potential difference) were obtained for the two analytes, namely at $0.630 \mathrm{~V}$ for RA and $0.530 \mathrm{~V}$ for PCA, enabling their simultaneous determination from Melissa officinallis, where they naturally coexist. Other phenolic compounds commonly found in related samples (CAFA, CGA, GLA, coumaric acid, 2,5 dihydroxybenzoic acid and rutin) affected the peak currents of RA and PCA only if they were present in a 3-fold excess. Wang et al. [33] showed that 100 fold of L-proline, glycine, isoleucine, phenol and less than 20 fold of cysteine and cystine did not interfere in RA determination on a GCE in PBS pH 7.40 , whereas the presence of quercetin reduces the RA peak current. In these conditions, applying the standard addition method the content of RA in Chinese herbal medicine was quantified with recoveries varying from $97.90 \%$ to $105.18 \%$ at controlled potential. Using SWV at CPE/Per-Au-BMI $\mathrm{PF}_{6}-\mathrm{CTN}$, RA was determined with good selectivity in the presence of potential interferents as a 3-fold excess of luteolin, rutin and GCA and a 10-fold excess of GLA, esculetin, ascorbic and benzoic acid caused less than $6.5 \%$ changes in the analyte oxidation signal [29]. CPE/Lacc-BMI $\mathrm{PF}_{6}$ was $100 \%$ sensitive to RA but also to other electroactive species, such as adrenaline (63.0\%), CAFA and CGA (25-22.0\%), catechin and rutin (about $9.0 \%$ ) and showed no response to other common polyphenolic compounds. Thus, the CPE/Lacc-BMI PF 6 [16], the CPE/Per-BMI-Tf2N-CS [52] and the biomimetic $\mathrm{CPE} / \mathrm{Fe}(\mathrm{III}) \mathrm{Zn}$ (II) sensor [30] were applied to SWV determination of RA in lemon balm plant extracts without the interference of hesperetin, hesperidin, $m$-coumaric acid, naringenin and naringin. In the case of laccase-based biosensors, a decrease in the electrode response was noticed in the presence of GLA, which was explained by the inhibition effect that gallic acid could have against this enzyme $[7,53,63]$. Possible chemical interferences from growth media (sugars, thiamine, mineral salts, and growth elicitors), which result in a decrease in the biosensors responses, were eliminated during the extraction steps performed to real samples before TPC evaluation $[7,59]$. 
It must be emphasized that, in most cases, the results yielded for the determination of either the RA or the total polyphenolic content of different samples, using the above mentioned (bio)sensors correlated well with those obtained by the chromatographic methods.

On a closer examination of Table 1, it can be seen that many of the electroanalytical methods developed for the quantitative determination of RA have a linearity range of about one order of magnitude, with LODs at the level of $10^{-7}$ or $10^{-6} \mathrm{M}$ RA. However, using SWSV at GCE [33] and DPV at PGE [17], the detection limits reached the nanomolar level and the linear concentration ranges extended up to three orders of magnitude.

\subsection{Electrochemical Methods in the Antioxidant Activity Assessment of $R A$ and $R A$ Containing Extracts}

Both the antioxidant activity and the electrochemical behavior of a compound depend strongly on its structure, e.g., on the number and position of the phenolic groups $[69,70]$.

Electrochemical methods became important tools in the assessment of antioxidant levels and in the evaluation of their antioxidant activity in various samples (plants, food, clinical, etc.) [39] due to the following assumptions: (i) all natural or dietary antioxidants (mainly including polyphenolic compounds, E and C vitamins) possess a native electroactivity [44] and (ii) they have the same conceptual base as the antioxidants action mechanism in in vitro systems.

Electrochemical techniques allow both the simultaneous estimation of the samples total antioxidants content (a quantitative measure representing the global amount of reducing species, estimated based on the anodic peak currents or areas and, usually, expressed as equivalent of a given antioxidant contained in the analyzed sample, like RAE in plant extracts $[7,8,55])$ as well as the evaluation of their antioxidant activity, defined as the ability of a compound (or a mixture of compounds) to inhibit the oxidative degradation of various species (i.e., lipid peroxidation) and which is a qualitative characteristic, indicating the reducing power of the antioxidants, conceptually related to their oxidation potential values $[9,39,40,43]$. Since the current is an additive quantity, the electrochemical signal should contain the contribution of all similar electroactive analytes existing in the sample, whereas the oxidation potential is correlated with the antioxidant activity, i.e., peaks with low oxidation potential values were associated with high antioxidant activity [41] (e.g., RA with oxidation peak potential at $0.620 \mathrm{~V}$ at GCE in acetate buffer solution (ABS) $\mathrm{pH} 4.50$ ), while peaks with higher ones with low antioxidant activity (e.g., $0.850 \mathrm{~V}$ at GCE in $\mathrm{ABS}$ pH 4.50 for $p$-coumaric acid) [71].

In the field of antioxidants, the "total phenolic content" is a measure of quality, which is traditionally assessed by the Folin-Ciocalteu spectrophotometric method, despite the fact that it usually overestimates the phenolic content. Therefore, electroanalytical methods are important alternatives to the spectrophotometric ones in the determination of the "total phenolic content" and antioxidant activity [44].

Other advantages of using electrochemical techniques to evaluate the antioxidant activity of compounds/samples are:

(i) As the electrochemical methods are electron-transfer-based assays, they can be considered as direct tests, because they do not use reactive species, but they exploit the chemical-physical properties of the analytes able to participate in electrochemical reactions (redox reactions) further used to evaluate the overall reducing power of the antioxidant compounds.

(ii) The suitable selection of the oxidation potential, allowed by electrochemical methods, enables a more selective measurement of antioxidant levels (which are more realistic than those found by spectrophotometric assays) and of the antioxidant activity (by the oxidation signals relative position) in complex environments, such as biological or food samples. On the other hand, using electrochemistry, direct information about the antioxidants with different antioxidant activity can be obtained by a decrease in the oxidation potential [40]. Using flow injection (FI) analysis with detection at a GCE, Blasco et al. [72] have introduced the concept of "Electrochemical Index" (EI), representing the "total polyphenolic" content obtained from electrochemistry. According to this concept, the total amount of polyphenols is obtained by nonselective oxidation of all 
antioxidants at a higher potential (e.g., $0.800 \mathrm{~V}$ in $\mathrm{pH} 7.50$ ), whereas different fractions of them can be evaluated by modifying the oxidation potential to lower values (e.g., the fractions of polyphenols with expected intermediate antioxidant power and those with high antioxidant capacity were obtained just by changing the oxidation potential at 0.500 and $0.300 \mathrm{~V}$ ). From a quantitative point of view, TPC was always higher than EI due to the inherent selectivity of EI in the determination of their total content in comparison with the spectrophotometric protocol. Nevertheless, the "Electrochemical Index" was well correlated with the spectrophotometrically obtained "total phenolics" ( $r=0.95)$.

(iii) Electrochemical approaches involve few instrumental requirements [40]; using the same equipment (potentiostat/galvanostat) and few resources (a set of electrodes), several methods can be applied to get various pieces of information that can help to obtain more accurate conclusions and a better understanding of the investigated phenomena/actions [73].

In the literature, there are some reviews that present detailed and critical discussions on both most widely used and also new methods applied for the evaluation of the antioxidant activity of different matrices so that the various assays can be employed "in their correct places to meet their needs" $[39,40,74]$.

A direct current polarographic method (DCP) at the dropping mercury electrode (DME) was used for the antioxidant activity determination using $\mathrm{H}_{2} \mathrm{O}_{2}$ in Clark and Lubs (CL) buffer of $\mathrm{pH}$ 9.80. In these conditions, the HydroxoPerhydroxoMercury (II) complex $\left[\mathrm{Hg}\left(\mathrm{O}_{2} \mathrm{H}\right)(\mathrm{OH})\right](\mathrm{HPMC})$ was formed and its anodic limiting current decreased upon the addition of antioxidants [75]. Recently, Stojićević et al. [76] optimized this method for antioxidant capacity estimation of samples with low solubility in water. The percentage of the initial HPMC anodic current decrease recorded upon each addition of the investigated antioxidant compounds (or complex samples) was calculated and plotted versus the antioxidant amount (or the sample volume). The slope of the obtained dependence $(\% / \mathrm{mol}$ or $\% / \mathrm{mL}$ ) was used to evaluate the antioxidant capacity of individual compounds or of the complex samples, respectively. Using this principle, RA antioxidant capacity was found to be $23.12 \pm 0.60 \% / \mathrm{mol}$.

A disposable electrochemical DNA biosensor constructed by the deposition of a surface layer of calf thymus double stranded (ds) DNA onto a C-SPE was used for the voltammetric assessment of the antioxidant activity of the standards RA and CAFA and of plant extracts containing RA and/or CAFA. The DPV peak current of the redox marker $\left[\mathrm{Co}(\mathrm{phen})_{3}\right]^{3+}$ was employed for $\mathrm{DNA}_{\mathrm{ds}}$ quantification, before and after the sensor pretreatment in the cleavage mixture ([Fe(EDTA) $]^{-}$complex and $\mathrm{H}_{2} \mathrm{O}_{2}$, without or with an antioxidant, under electrochemical reduction conditions). During the cleavage reaction, a part of the $\mathrm{DNA}_{\mathrm{ds}}$ from the electrode surface was damaged resulting in a decreased amount of bound redox marker and thus to a lower $\left[\mathrm{Co}(\text { phen })_{3}\right]^{3+}$ DPV peak current. The antioxidant activity of RA, CAFA and plant extracts was confirmed by their protective action on the surface attached $\mathrm{DNA}_{\mathrm{ds}}$ against its damage, when they were added to the cleavage mixture. The antioxidant activities of the lemon balm, oregano, thyme and agrimony extracts, expressed as an equivalent of RA $(\mathrm{mg} / \mathrm{mL})$, were $0.046,0.039,0.028$ and 0.021 , respectively [77].

A rapid FI method with detection performed in a thin-layer electrochemical cell using a working GCE operating amperometrically at $0.500 \mathrm{~V}$ was used to evaluate the antioxidant activity of methanolic herb extracts from the Labiatae family. In the mentioned experimental conditions, hydrodynamic voltammetric results emphasized that the antioxidant activity of certain compounds, selected based on the data reported in literature about their presence in the investigated herbs, decreased as follows: carnosic acid $>$ quercetin $>$ RA $>$ kaempferol $>$ CAFA $>$ galangin, whereas ferulic and $p$-coumaric acid, thymol and hesperitin have very low or no antioxidant activity. Among the analyzed herbs, rosemary and sage exhibited the highest antioxidant power, probably due to their high content of RA and carnosic acid. The data obtained by the FI electrochemical method correlated well with those obtained by the spectrophotometric DPPH (2, 2-diphenyl-1-picrylhydrazyl radical) assay [71].

A comparison between the results of spectrophotometric and electroanalytical antioxidant activity assays of commercial dried herbal extracts was done by de Siqueira Leite et al. [78]. In order to 
establish the qualitative features used for identification, the anodic and cathodic peaks obtained by CV and SWV at GCE were evaluated to check the distinct voltammetric profiles of the investigated samples. The anodic peak potential, which expresses the reducing power, and the anodic peak current, which gives information about the swiftness of the electron transfer and the amount of antioxidant content, were acquired from DPV at GCE measurements and used to get an EI, which was compared with traditional radical scavenging assays. The TPC expressed as gallic acid equivalent (GLAE) and rutin equivalent $(\mathrm{RuE})$ were determined for each herbal extract by the Folin-Ciocalteu method and amperometry using a peroxidase carbon paste biosensor, respectively. The overall findings for TPC were in agreement with those obtained for antioxidant activity, the spectrometric and electrochemical results being well correlated.

Salvia officinalis L. bioactive properties (e.g., antioxidant, hepato and nephroprotective effects) are due to its polyphenol content, which consists mainly of rosmarinic acid isomers and derivatives with high superoxide scavenging activities. Sage's cytoprotective action on mammalian cells was voltammetrically investigated in vitro using a cell-based electrochemical biosensor consisting of commercially available poly (3,4-ethylenedioxythiophene)-SPE (PEDOT-SPE) modified with renal cell monolayers as the primary transducers for signal generation and biological sensing. CV studies revealed the fact that the sage extracts ameliorated $\mathrm{CCl}_{4}$-induced cytotoxicity, its protective action being indicated by the increases in the half maximal effective concentration $\left(\mathrm{EC}_{50}\right)$ values [79].

Cyclic voltammograms recorded for methanolic extracts of various spices showed different oxidation signals, with areas and potentials depending on the corresponding spice. It was found that the individual antioxidants of spices (GLA, RA, thymol, eugenol, and capsaicin) are oxidized at a GCE in $0.1 \mathrm{M} \mathrm{LiClO}_{4}$ in ethanol at very close potentials (around $1.200 \mathrm{~V}$ ), except GLA, which is more easily oxidized at $0.880 \mathrm{~V}$, whereas eugenol anodic peak appears at $1.000 \mathrm{~V}$. Based on these signals and using the total area of the oxidation steps, a CV method was developed for the evaluation of the antioxidant capacity of spices, expressed as the mg GLA/1 $g$ of dry spice. The antioxidant activity results obtained by voltammetry correlated well with other parameters characterizing the antioxidant properties of spices (total antioxidant activity, ferric reducing power, antiradical activity, and total content of phenolic compounds) [43].

The antioxidant activity of the micellar Brij ${ }^{\circledR} 35$ extracts of twenty types of spices was evaluated by DPV in PBS (pH 7.40) at a GCE modified with cerium dioxide nanoparticles (CeO2-Brij ${ }^{\circledR}$ 35/GCE). The voltammograms of the various spices micellar extracts presented different number of anodic peaks over a wide potentials range. Only the antioxidants present in the spices in a sufficiently high concentration displayed their oxidation signals in the DP voltammograms. Some of the signals were identified based on the oxidation potentials of the fifteen used standards, among them being also RA, obtained in the same experimental conditions. For example, RA oxidation peak (at about $0.130 \mathrm{~V}$ vs. $\mathrm{Ag} / \mathrm{AgCl}$ ) was identified in oregano, rosemary and red pepper extracts. The contributions of the main antioxidants to the electrochemical response of the micellar spices extracts were established using the standard addition method. The total area of the oxidation signals was employed for the assessment of the spices antioxidant activity, expressed in units of GLA weight per gram of dry spice. Positive correlations were found for the electrochemically established antioxidant activity and both the ferric reducing power and the DPPH spectrophotometric method results [80].

Starting from the hypotheses that phenolic acids protective effects against diseases are based on their interaction with the membrane lipid bilayer (LB) of various cell types, Filipe et al. [81] used complementary quantitative experimental approaches, including $\mathrm{CV}$, to characterize the interplay between RA, CA and CGA and lipid bilayers. Based on their redox characteristics, the interactions of the investigated phenolic acids with LB were studied electrochemically after their immobilization in the supported lipid bilayers (SLB) prepared on self-assembled monolayer (SAM) modified gold surfaces. Thus, CV measurements were realized using as working electrode a borosilicate glass slide, with a chromium undercoat, covered with a thin film of gold modified with an SAM of 3-mercaptopropionic acid that constituted the support of LB obtained using an one single component 
phase of 1-palmitoyl-2-oleoyl-sn-glycero-3-phosphocholine (POPC)-the lipid disordered $\left(l_{d}\right)$ phase-and the binary system POPC/Chol (where Chol stands for cholesterol) - the lipid ordered $\left(l_{0}\right)$ phase. The investigated phenolic acids interact with the SLB during the incubation period at room temperature. From the CV redox peaks, it was concluded that RA exhibited the highest LB partition and thus the highest affinity towards the membrane, confirming the fluorescence spectroscopy conclusions. The surface coverage values for RA, also obtained from CV data, depended on the lipid phase, showing a lower incorporation of RA in $l_{o}$ phase bilayers (containing Chol) than in $l_{d}$ bilayers, in good agreement with the membrane/water partition coefficient values obtained for RA. The linear dependence of the maximum reduction current density on the potential scan rate indicated that the electroactive species were adsorbed in the vicinity of the electrode surface, confirming the presence of membrane-bound polyphenols and the fact that both catechol and quinone forms of RA or CA interacted with the bilayer lipids.

\subsection{Electrochemical Investigation of $R A$ Interaction with Biological Important Compounds}

As RA is a natural compound with many beneficial health effects, commonly used as both a medicinal substance and food supplement, it is important to investigate and understand its behavior and interaction with other biologically significant species. As many RA actions involve charge transfer processes, electrochemical techniques, especially $\mathrm{CV}$, are useful, at least as complementary techniques, for the elucidation of RA behavior in biological systems.

It is considered that antioxidants can interact and thus generate a synergistic inhibition effect of lipid oxidation. The variations of the antioxidant activity observed for mixtures of RA esters and $\alpha$-tocopherol $(\alpha-\mathrm{TOH})$ could be due to the regeneration of an antioxidant by the other. It is known that antioxidants with lower reduction potentials are thermodynamically more stable and donate the electrons to antioxidants with higher reduction potential. As CV is often the technique of choice in investigating the oxidation-reduction potentials of different analytes, it was used to examine the interaction of RA and its esters with $\alpha-\mathrm{TOH}$. CVs of RA and its esters recorded at GCE in acetonitrile presented anodic peaks at much higher potentials $(1115-1137 \mathrm{mV}$ vs. $\mathrm{Ag} / \mathrm{AgCl})$ than $\alpha-\mathrm{TOH}(634.9 \mathrm{mV})$. Despite the fact that, in aqueous solutions (PBS pH 7.00, both in the absence and presence of Tween 20) the RA oxidation peak potentials decreased drastically ( $359 \pm 19.2$ and $394 \pm 16.9 \mathrm{mV}$, respectively), they remain still higher than those of the water soluble antioxidant, Trolox ( $275.0 \pm 12.0$ and $298.7 \pm 18.5 \mathrm{mV}$, respectively) and of $\alpha-\mathrm{TOH}$ in micellar medium $(263.3 \pm 2.3 \mathrm{mV})$, suggesting that $\alpha-\mathrm{TOH}$ is thermodynamically preferred to donate electrons to RA [82].

Human serum albumin (HSA) interaction with RA was confirmed using CV at GCE in PBS ( $\mathrm{pH}$ 7.40) when, in the presence of HSA, the RA oxidation and reduction peak currents decreased and the potentials shifted towards more positive and negative values, respectively, emphasizing the formation of an electroinactive HSA-RA complex [21].

$\mathrm{N} \varepsilon$-(carboxymethyl) lysine (CML) is a typical marker of advanced glycation end products largely found in food. Studies on mice have proven that the administration of CML-enriched diets resulted in endothelial dysfunction and damages of liver and kidney by oxidative stress. It was observed that the natural polyphenolic antioxidants inhibit the CML formation, one of the reasons being the fact that the $o$-benzoquinones generated via polyphenol oxidation react with the amino groups of CML, thus controlling the lysine derivative levels. The interaction of different polyphenols, among them being RA, with CML evaluated by the decrease in the corresponding benzoquinone reduction peak currents $\left(\mathrm{I}_{\mathrm{pc}}\right)$ in the presence of $\mathrm{CML}$ recorded by $\mathrm{CV}$ at the GCE at $\mathrm{pH}$ values relevant for food (pH 5.00, meat; $\mathrm{pH} 7.00$, milk; $\mathrm{pH} 8.00$, egg-based products). $\mathrm{pH} 7.00$ and $\mathrm{pH} 8.00$ were the best conditions for the interaction of non-flavonoid benzoquinones with $\mathrm{CML}$, whose reactivity according to the $\mathrm{I}_{\mathrm{pc}}$ decrease by $\mathrm{CML}$ varied as follows: $\mathrm{PCA}>$ catechol $(\mathrm{C})>\mathrm{CAFA}>\mathrm{RA} \approx 4$-methylcatechol $(4 \mathrm{MC})>$ CGA [83]. Using a similar approach, the same researcher group established the reactivity order of different $o$-benzoquinones with L-lysine/L-cysteine, considering the parent polyphenol, as follows: $\mathrm{PCA} \approx \mathrm{C}>4 \mathrm{MC} \approx \mathrm{CAFA}>\mathrm{RA}>\mathrm{GCA}[84]$. 


\subsection{Dynamic Methods with Electrochemical Detection for RA and RA Containing Samples Analysis}

As already stated, due to the presence of phenolic hydroxyl groups in their structure, polyphenolic acids, including RA, are electroactive species and thus their oxidation at different electrodes constitutes the basis for their electrochemical detection (ECD) in dynamic (flow injection or separation) methods (Table 2). It was reported that, in comparison to UV detection, ECD can improve the selectivity and sensitivity of chromatographic methods and can provide more information about the substances with redox properties [85]. ECD can be performed by coulometry, which measures the electrical charge consumed for the total oxidation or reduction of the analyte during its pass through the detector cell, or amperometry, which measures the current generated by the oxidation or a reduction of the analyte flowing through the detector cell [46]. In the ECD employed in chromatographic analysis of phenolic acids, the measured signal is mainly the peak current (calculated by measuring the peak height or area) of the analytes and it strongly depends on the potential applied at the working electrode. Usually, the optimum working potential is determined by hydrodynamic voltammetric studies [86].

The contents of thirteen phenolic acids, including RA, in thirty-six monofloral honey samples of three types were evaluated using high-performance liquid chromatography (HPLC) with ECD and the chromatographic fingerprints of these samples were established. By combining the common chromatographic information (e.g., peak areas) with chemometric methods (principal component analysis-PCA-And discriminant analysis), the honey samples could be differentiated by their floral origin [87] (Table 2). HPLC-ECD combined with PCA and orthogonal projections to latent structures discriminant analysis were recently applied to establish the chromatographic fingerprints of acacia raw honey and raw honey treated with macroporous adsorption resins and to discriminate the adulterated (resins-treated) products [88,89]. Liquid chromatography (LC) with ECD combined with PCA and cluster analysis could detect acacia honey adulteration by the addition of different levels $(5-50 \%, w / w)$ of rape honey using as principal markers GCA (the most predominant phenolic acid in acacia honey) and ellagic acid (the phenolic acid mostly present in rape honey). But it must be outlined that RA exists in low amounts in both types of honey [90]. The performances of HPLC-ECD quantification of eight phenolic acids and nine flavonoids in extracts of seven honey samples of different floral origin were improved using a sugaring-out assisted liquid-liquid extraction method before the chromatographic analysis [85] (Table 2).

Table 2. Results of RA quantification using different separation techniques with electrochemical detection (ECD).

\begin{tabular}{|c|c|c|c|c|c|}
\hline Technique & Electrode/Potential (V) & Linear Range (g/mL) & LOD $(\mathrm{g} / \mathrm{mL})$ & Sample & Ref \\
\hline CE-AD & $\mathrm{CDE} / 0.900 *$ & $5.00 \times 10^{-6}-5.00 \times 10^{-4}$ & $1.00 \times 10^{-6}$ & Rosemary & [86] \\
\hline CE-AD & $\mathrm{CDE} / 0.950 *$ & $1.00 \times 10^{-6}-1.00 \times 10^{-4}$ & $1.30 \times 10^{-8}$ & Honeybee-collected pollen $* * *$ & [92] \\
\hline HPLC-ECD & GCE $/ 0.900 * *$ & $1.05 \times 10^{-7}-2.00 \times 10^{-5}$ & $1.70 \times 10^{-8}$ & Honey & [87] \\
\hline HPLC-ECD & 0.900 & $5.60 \times 10^{-7}-1.30 \times 10^{-5}$ & $2.10 \times 10^{-8}$ & Honey & [88] \\
\hline HPLC-ECD & GCE $/ 1.000 * *$ & $5.00 \times 10^{-8}-2.50 \times 10^{-5}$ & $9.20 \times 10^{-7}(\mathrm{~g} / \mathrm{kg})$ & Honey & [85] \\
\hline 3HPLC-3ECD & GCE $/ 0.700 * *$ & $1.00 \times 10^{-8}-2.50 \times 10^{-5}(\mathrm{M})$ & $3.90 \times 10^{-15}(\mathrm{M})$ & Salvia miltiorrhiza & [91] \\
\hline IL/W MELC-ECD & $\mathrm{GCE} / 0.700 * *$ & $5.00 \times 10^{-6}-2.50 \times 10^{-4}$ & $1.01 \times 10^{-7}$ & Danshen & [93] \\
\hline $\begin{array}{l}{ }^{*} \text { vs. SCE; }{ }^{* *} \mathrm{vs} \\
\text { amperometric } \\
\text { liquid chroma } \\
\text { ionic liquid-W } \\
1.0 \% w / v \text { SDS, }\end{array}$ & $\begin{array}{l}\text { r microemulsion }(C \\
\text { o } w / v \text { n-butanol, } 95 .\end{array}$ & $2 \%$ w/v 1-hexyl-3-met & $\begin{array}{l}\text { imel: GCE: Gla } \\
\text { imidazolium l } \\
\text { chromatogra }\end{array}$ & $\begin{array}{l}\text { capillary electrophoresis } \\
\text { in-switching high-perforn } \\
\text { carbon electrode; MELC- } \\
\text { afluorophosphate [HMII } \\
\text { with electrochemical dete }\end{array}$ & $\begin{array}{l}\text { ith } \\
\text { nce } \\
\text { CD: } \\
{ }^{2} F_{6} \text {; } \\
\text { ion; }\end{array}$ \\
\hline
\end{tabular}

A three-channel column-switching HPLC system with two oxidative (for phenolic acids) and one reductive (for tanshinones) detection channels was developed for the sensitive determination of these compounds in Salvia miltiorrhiza. The analytes were divided into two groups of phenolic acids that are readily electrochemically oxidized and one group containing tanshinones, which comprise in their structure quinonyl groups that can be electroreduced. Each switching valve was rotated to change the elute flow way so that compounds of the different groups were directed into the corresponding detection channels. The optimum detection potentials applied to the GCEs used as working electrodes 
were $0.700 \mathrm{~V}$ for the two groups of oxidizable compounds (including $\mathrm{RA}$ ) and $0.200 \mathrm{~V}$ vs. $\mathrm{Ag} / \mathrm{AgCl}$ for the category of reducible species (tanshinones) [91].

Based on the previously discussed relationship between the electrochemical behavior of a compound and its antioxidant activity, several on-line HPLC-ED or FIA-ED methods, using both coulometric or amperometric detection, have been developed also to assess the antioxidant activity of PCs in various matrixes [94].

\section{Conclusions}

The data presented in this review were compiled after carefully studying, comparing, and correlating the information found in over ninety articles published in the scientific literature related to this topic in the last twenty-five years. This paper briefly presented the most significant information (e.g., occurrence, properties and uses) regarding rosmarinic acid and emphasized the most important features of electroanalysis in comparison to other analytical methods (e.g., selectivity, rapidity, simplicity, applicability in colored and turbid solutions, low-cost, user- and eco-friendly), in order to be chosen as an analytical tool for RA assessment. The used (bio) sensors were also indicated and briefly described. It must be pointed out that the electrochemical methods not only allow the quantification of RA but also enable the investigation and understanding of the charge transfer processes that underlie certain properties and biochemical actions of it. Even so, there are still many aspects to investigate and improve in the RA electroanalysis. Perhaps one of the most important issues is related to increasing the selectivity towards structurally related species, e.g. other HCAs, and this can be achieved by the development of chemically modified electrodes, for example, using molecularly imprinted polymers (MIP), which also could result in lower detection limits. Having more selective sensors, multi-electrode devices could be designed to perform fast simultaneous multi-species analysis. Last but not least, cost effective and environmental safe tools and approaches should be designed by using eco-friendly and cheap electrodes, such as the PGE, and surface modification methods (e.g., electroactivation) [95].

Author Contributions: Conceptualization \& methodology, I.G.D. and M.C.C.; resources \& data curation, I.G.D., M.B. and D.E.P.; writing - original draft preparation, I.G.D., D.E.P. and M.C.C.; visualization, I.G.D. and M.B.; writing-review and editing, I.G.D., M.B., D.E.P. and M.C.C. All authors have read and agreed to the published version of the manuscript.

Funding: This research received no external funding.

Conflicts of Interest: The authors declare no conflict of interest.

\section{References}

1. Oroian, M.; Escriche, I. Antioxidants: Characterization, natural sources, extraction and analysis. Food Res. Int. 2015, 74, 10-36. [CrossRef]

2. Carvalho Costa, D.; Costa, H.S.; Albuquerque, T.G.; Ramos, F.; Castilho, M.C.; Sanches-Silva, A. Advances in phenolic compounds analysis of aromatic plants and their potential applications. Trends Food Sci. Technol. 2015, 45, 336-354. [CrossRef]

3. Bounegru, A.V.; Apetrei, C. Voltammetric sensors based on nanomaterials for detection of caffeic acid in food supplements. Chemosensors 2020, 8, 41. [CrossRef]

4. Skendi, A.; Irakli, M.; Chatzopoulou, P. Analysis of phenolic compounds in Greek plants of Lamiaceae familyby HPLC. J. Appl. Res. Med. Aromat. Plants 2017, 6, 62-69. [CrossRef]

5. Ismail, N.I.; Sornambikai, S.; Kadir, M.R.A.; Mahmood, N.H.; Zulkifli, R.M.; Shahir, S. Evaluation of radical scavenging capacity of polyphenols found in natural Malaysian honeys by voltammetric techniques. Electroanalysis 2018, 30, 2939-2949. [CrossRef]

6. Papuc, C.; Goran, G.V.; Predescu, C.N.; Nicorescu, V.; Stefan, G. Plant polyphenols as antioxidant and antibacterial agents for shelf-life extension of meat and meat products: Classification, structures, sources, and action mechanisms. Compr. Rev. Food Sci. Food Saf. 2017, 16, 1243-1268. [CrossRef] 
7. Litescu, S.C.; Eremia, S.A.V.; Bertoli, A.; Pistelli, L.; Radu, G.-L. Laccase-Nafion based biosensor for the determination of polyphenolic secondary metabolites. Anal. Lett. 2010, 43, 1089-1099. [CrossRef]

8. Diaconu, M.; Litescu, S.C.; Radu, G.L. Laccase-MWCNT-chitosan biosensor-A new tool for total polyphenolic content evaluation from in vitro cultivated plants. Sens. Act. B 2010, 145, 800-806. [CrossRef]

9. Teixeira, J.; Gaspar, A.; Garrido, E.M.; Garrido, J.; Borges, F. Hydroxycinnamic acid antioxidants: An electrochemical overview. BioMed Res. Int. 2013, 3, 251754. [CrossRef]

10. Shahidi, F.; Chandrasekara, A. Hydroxycinnamates and their in vitro and in vivo antioxidant activities. Phytochem. Rev. 2010, 9, 147-170. [CrossRef]

11. Wang, S.; Zhu, F. Tamarillo (Solanum betaceum): Chemical composition, biological properties, and product innovation. Trends Food Sci. Technol. 2020, 95, 45-58. [CrossRef]

12. Newair, E.F.; Abdel-Hamid, R.; Kilmartin, P.A. Mechanism of chicoric acid electrochemical oxidation and identification of oxidation products by liquid chromatography and mass spectrometry. Electroanalysis 2017, 29, 850-860. [CrossRef]

13. Ozdokur, K.V.; Kocak, C.C. Simultaneous determination of rosmarinic acid and protocatechuic acid at poly(o-phenylenediamine)/Pt nanoparticles modified glassy carbon electrode. Electroanalysis 2019, 31, 2359-2367. [CrossRef]

14. Khojasteh, A.; Mirjalili, M.H.; Hidalgo, D.; Corchete, P.; Palazon, J. New trends in biotechnological production of rosmarinic acid. Biotechnol. Lett. 2014, 36, 2393-2406. [CrossRef] [PubMed]

15. Sik, B.; Kapcsándi, V.; Székelyhidi, R.; Hanczné, E.L.; Ajtony, Z. Recent advances in the analysis of rosmarinic acid from herbs in the Lamiaceae family. Nat. Prod. Commun. 2019, 14, 1-10. [CrossRef]

16. Franzoi, A.C.; Dupont, J.; Spinelli, A.; Vieira, I.C. Biosensor based on laccase and an ionic liquid for determination of rosmarinic acid in plant extracts. Talanta 2009, 77, 1322-1327. [CrossRef]

17. Gil, E.S.; Enache, T.A.; Oliveira-Brett, A.M. Redox behaviour of verbascoside and rosmarinic acid. Comb. Chem. High Throughput Screen. 2013, 16, 92-97. [CrossRef]

18. Beiginejad, H.; Moradi, M.; Paziresh, S.; Farahani, H. Thermodynamic and mechanistic study of the electrochemical oxidation of rosmarinic acid. J. Electrochem. Soc. 2018, 165, H698-H704. [CrossRef]

19. David, I.G.; Buleandră, M.; Popa, D.E.; Bîzgan, A.-M.C.; Moldovan, Z.; Badea, I.-A.; Iorgulescu, E.E.; Tekiner, T.A.; Basaga, H. Voltammetric determination of polyphenolic content as rosmarinic acid equivalent in tea samples using pencil graphite electrodes. J. Food Sci. Technol. 2016, 53, 2589-2596. [CrossRef]

20. Topal, M.; Gulcin, I. Rosmarinic acid: A potent carbonic anhydrase isoenzymes inhibitor. Turk. J. Chem. 2014, 38, 894-902. [CrossRef]

21. Peng, X.; Wang, X.; Qi, W.; Su, R.; He, Z. Affinity of rosmarinic acid to human serum albumin and its effect on protein conformation stability. Food Chem. 2016, 192, 178-187. [CrossRef] [PubMed]

22. Amoah, S.K.S.; Sandjo, L.P.; Kratz, J.M.; Biavatti, M.W. Rosmarinic acid-Pharmaceutical and clinical aspects. Planta Med. 2016, 82, 388-406. [CrossRef] [PubMed]

23. Park, S.U.; Uddin, M.R.; Xu, H.; Kim, Y.K.; Lee, S.Y. Biotechnological applications for rosmarinic acid production in plant. Afr. J. Biotechnol. 2008, 7, 4959-4965.

24. Ziyatdinova, G.K.; Budnikov, H.C. Spice Antioxidants as Objects of Analytical Chemistry. J. Anal. Chem. 2018, 73, 946-965. [CrossRef]

25. Rocha, J.; Eduardo-Figueira, M.; Barateiro, A.; Fernandes, A.; Brites, D.; Bronze, R.; Duarte, C.M.M.; Serra, A.T.; Pinto, R.; Freitas, M.; et al. Anti-inflammatory effect of rosmarinic acid and an extract of Rosmarinus officinalis in rat models of local and systemic inflammation. Basic Clin. Pharmacol. 2015, 116, 398-413. [CrossRef]

26. Ertas, A.; Boga, M.; Yilmaz, M.A.; Yesil, Y.; Tel, G.; Temel, H.; Hasimi, N.; Gazioglu, I.; Ozturk, M.; Ugurlu, P. A detailed study on the chemical and biological profiles of essential oil and methanol extract of Thymus nummularius (Anzer tea): Rosmarinic acid. Ind. Crops Prod. 2015, 67, 336-345. [CrossRef]

27. Asadi, N.; Ramezanzadeh, M.; Bahlakeh, G.; Ramezanzadeh, B. Theoretical MD/DFT computer explorations and surface-electrochemical investigations of the zinc/iron metal cations interactions with highly active molecules from Lemon balm extract toward the steel corrosion retardation in saline solution. J. Mol. Liq. 2002, 310, 113220. [CrossRef]

28. Andrade, P.; Ferreres, F.; Gil, M.I.; Tomas-Barberan, F.A. Determination of phenolic compounds in honeys with different floral origin by capillary zone electrophoresis. Food Chem. 1997, 60, 79-84. [CrossRef] 
29. Brondani, D.; Zapp, E.; Cruz Vieira, I.; Dupont, J.; Weber Scheeren, C. Gold nanoparticles in an ionic liquid phase supported in a biopolymeric matrix applied in the development of a rosmarinic acid biosensor. Analyst 2011, 136, 2495-2505. [CrossRef]

30. Santhiago, M.; Peralta, R.A.; Neves, A.; Micke, G.A.; Vieira, I.C. Rosmarinic acid determination using biomimetic sensor based on purple acid phosphatase mimetic. Anal. Chim. Acta 2008, 613, 91-97. [CrossRef]

31. Mohamadi, M.; Mostafavi, A.; Torkzadeh-Mahani, M. Voltammetric determination of rosmarinic acid on chitosan/carbon nanotube composite-modified carbon paste electrode covered with DNA. J. Electrochem. Soc. 2015, 162, B344-B349. [CrossRef]

32. Eremia, S.A.V.; Radu, G.-L.; Litescu, S.-C. Monitoring of rosmarinic acid accumulation in sage cell cultures using laccase biosensor. Phytochem. Anal. 2013, 24, 53-58. [CrossRef] [PubMed]

33. Wang, J.; Zhang, K.; Zhou, J.; Liu, J.; Ye, B. Electrochemical properties of rosmarinic acid and its analytical application. Sensor Lett. 2013, 11, 305-310. [CrossRef]

34. Qu, L.; Xu, H.; Jia, W.; Jiang, H.; Xie, J. Rosmarinic acid protects against MPTP-induced toxicity and inhibits ironinduced $\alpha$-synuclein aggregation. Neuropharmacology 2019, 144, 291-300. [CrossRef] [PubMed]

35. Alkam, T.; Nitta, A.; Mizoguchi, H.; Itoh, A.; Nabeshima, T. A natural scavenger of peroxynitrites, rosmarinic acid, protects against impairment of memory induced by Aß25-35. Behav. Brain Res. 2007, 180, 139-145. [CrossRef] [PubMed]

36. Guldiken, B.; Ozkan, G.; Catalkaya, G.; Ceylan, F.D.; Yalcinkaya, I.E.; Capanoglu, E. Phytochemicals of herbs and spices: Health versus toxicological effects. Food Chem. Toxicol. 2018, 119, 37-49. [CrossRef]

37. Osipova, V.P.; Berberova, N.T.; Gazzaeva, R.A.; Kudryavtsev, K.V. Application of new phenolic antioxidants for cryopreservation of sturgeon sperm. Cryobiology 2016, 72, 112-118. [CrossRef]

38. Hsueh, C.; Wu, C.; Chen, B. Polyphenolic compounds as electron shuttles for sustainable energy utilization. Biotechnol. Biofuels 2019, 12, 271. [CrossRef]

39. Sochor, J.; Dobes, J.; Krystofova, O.; Ruttkay-Nedecky, B.; Babula, P.; Pohanka, M.; Jurikova, T.; Zitka, O.; Adam, V.; Klejdus, B.; et al. Electrochemistry as a tool for studying antioxidant properties. Int. J. Electrochem. Sci. 2013, 8, 8464-8489.

40. Blasco, A.J.; Crevillen, A.G.; Gonzalez, M.C.; Escarpa, A. Direct electrochemical sensing and detection of natural antioxidants and antioxidant capacity in vitro systems. Electroanalysis 2007, 19, 2275-2286. [CrossRef]

41. Bard, A.J.; Faulkner, L.R. Electrochemical Methods: Fundamentals and Applications; John Wiley \& Sons: New York, NY, USA, 2001.

42. Di Carlo, G.; Curulli, A.; Trani, A.; Zane, D.; Ingo, G.M. Enhanced electrochemical response of structurally relatedantioxidant at nanostructured hybrid films. Sens. Actuat. B 2014, 191, 703-710. [CrossRef]

43. Ziyatdinova, G.K.; Budnikov, H.C. Evaluation of the antioxidant properties of spices by cyclic voltammetry. J. Anal. Chem. 2014, 69, 990-997. [CrossRef]

44. Escarpa, A. Food electroanalysis: Sense and simplicity. Chem. Rec. 2012, 12, 72-91. [CrossRef] [PubMed]

45. Gil, E.S.; Couto, O.R. Flavonoid electrochemistry: A review on the electroanalytical applications. Rev. Bras. Farmacogn. 2013, 23, 542-558. [CrossRef]

46. Dobes, J.; Zitka, O.; Sochor, J.; Ruttkay-Nedecky, B.; Babula, P.; Beklova, M.; Kynicky, J.; Hubalek, J.; Klejdus, B.; Kizek, R.; et al. Electrochemical tools for determination of phenolic compounds in plants. A review. Int. J. Electrochem. Sci. 2013, 8, 4520-4542.

47. Petrucci, R.; Astolfi, P.; Greci, L.; Firuzi, O.; Saso, L.; Marrosu, G. A spectroelectrochemical and chemical study on oxidation of hydroxycinnamic acids in aprotic medium. Electrochim. Acta 2007, 52, 2461-2470. [CrossRef]

48. Brett, C.M.A.; Oliveira-Brett, A.M. Electrochemistry: Principles, Methods and Applications; Oxford Science Publications: Oxford, UK, 1993.

49. Bilgi, M.; Sahina, E.M.; Ayranci, E. Sensor and biosensor application of a new redox mediator: Rosmarinic acid modified screen-printed carbon electrode for electrochemical determination of NADH and ethanol. J. Electroanal. Chem. 2018, 813, 67-74. [CrossRef]

50. Gosser, D.K. Cyclic Voltammetry: Simulation and Analysis of Reaction Mechanisms; Wiley-VCH: New York, NY, USA, 1993.

51. Gonçalves, D.; Couto, R.O.; Conceição, E.C.; Reis, N.S.; Gil, E.S. Voltametria de pulso diferencial (VPD) em estado sólido de manchas de cromatografia de camada delgada (CCD): Um novo método de análise para fitoativos antioxidantes. Quim. Nova 2011, 34, 330-334. [CrossRef] 
52. Dos Santos Maguerroski, K.; Fernandes, S.C.; Franzoi, A.C.; Vieir, I.C. Pine nut peroxidase immobilized on chitosan crosslinked with citrate and ionic liquid used in the construction of a biosensor. Enzym. Microb. Technol. 2009, 44, 400-405. [CrossRef]

53. Eremia, S.A.V.; Vasilescu, I.; Radoi, A.; Litescu, S.C.; Radu, G.L. Disposable biosensor based on platinum nanoparticles-reduced graphene oxide-laccase biocomposite for the determination of total polyphenolic content. Talanta 2013, 110, 164-170. [CrossRef]

54. Penu, R.; Vasilescu, I.; Eremia, S.A.V.; Gatea, F.; Radu, G.-L.; Litescu, S.-C. Development of a nanocomposite system and its application in biosensors construction. Cent. Eur. J. Chem. 2013, 11, 968-978. [CrossRef]

55. Diaconu, M.; Litescu, S.C.; Radu, G.L. Bienzymatic sensor based on the use of redox enzymes and chitosan-MWCNT nanocomposite. Evaluation of total phenolic content in plant extracts. Microchim. Acta 2011, 172, 177-184. [CrossRef]

56. Almeida, L.C.; Correia, R.D.; Squillaci, G.; Morana, A.; La Cara, F.; Correia, J.P.; Viana, A.S. Electrochemical deposition of bio-inspired laccase-polydopamine films for phenolic sensors. Electrochim. Acta 2019, 319, 462-471. [CrossRef]

57. Bîzgan, A.-M.C. Determinarea Voltametrică a Unor Compuși Polifenolici cu Acțiune Antioxidantă. (Voltammetric Determination of Polyphenolic Compounds with Antioxidant Action). Master's Thesis, University of Bucharest, Bucharest, Romania, June 2015.

58. Enache, T.A.; Oliveira-Brett, A.M. Phenol and para-substituted phenols electrochemical oxidation pathways. J. Electroanal. Chem. 2011, 655, 9-16. [CrossRef]

59. Simić, A.; Manojlović, D.; Šegan, D.; Todorović, M. Electrochemical behavior and antioxidant and prooxidant activity of natural phenolics. Molecules 2007, 12, 2327-2340. [CrossRef]

60. Chiorcea-Paquim, A.M.; Enache, A.T.; Gil, E.S.; Oliveira-Brett, A.M. Natural phenolic antioxidants electrochemistry: Towards a new food science methodology. Compr. Rev. Food Sci. Food Saf. 2020, 19, 1680-1726. [CrossRef]

61. Yang, J.; Chen, Y.; Zhen, X.-T.; Dong, X.; Ye, L.-H.; Zheng, H.; Cao, J. Oxidative metabolism of typical phenolic compounds of Danshen by electrochemistry coupled to quadrupole time-of-flight tandem mass spectrometry. Food Chem. 2020, 315, 126270. [CrossRef]

62. Garcia-Guzman, J.J.; Loez-Iglesias, D.; Marin, M.; Lete, C.; Lupu, S.; Palacios-Santander, J.M.; Cubillana-Aguilera, L. Electrochemical biosensors for antioxidants. In Advanced Biosensors for Health Care Applications, 1st ed.; Inamuddin Khan, R., Mohammad, A., Asiri, A.M., Eds.; Elsevier Inc.: Amsterdam, The Netherlands, 2019; pp. 104-146.

63. Stroble, J.K.; Stone, R.B.; Watkins, S.E. An overview of biomimetic sensor technology. Sens. Rev. 2009, 29, 112-119. [CrossRef]

64. Lee, J.H.; Jin, H.-E.; Desai, M.S.; Ren, S.; Kim, S.; Lee, S.-W. Biomimetic sensor design. Nanoscale 2015, 7, 18379-18391. [CrossRef]

65. Lu, L.; Hu, X.; Zhu, Z. Biomimetic sensors and biosensors for qualitative and quantitative analyses of five basic tastes. TrAC Trend. Anal. Chem. 2017, 87, 58-70. [CrossRef]

66. Rodriguez-Delgado, M.M.; Aleman-Nava, G.S.; Rodriguez-Delgado, J.M.; Dieck-Assad, G.; Martinez-Chapa, S.O.; Barcelo, D.; Parra, R. Laccase-based biosensors for detection of phenolic compounds. TrAC Trend. Anal. Chem. 2015, 74, 21-45. [CrossRef]

67. Betancor, L.; Johnson, G.R.; Luckarift, H.R. Stabilized laccases as heterogeneous bioelectrocatalysts. ChemCatChem 2013, 5, 46-60. [CrossRef]

68. Sýs, M.; Metelka, R.; Frangu, A.; Vytřas, K.; Arbneshi, T. Electrochemical study of Trametes Versicolor laccase compatibility to different polyphenolic substrates. Chemosensors 2017, 5, 9. [CrossRef]

69. Rice-Evans, C.A.; Miller, N.J.; Paganga, G. Structure-antioxidant activity relationship of flavonoids and phenolic acids. Free Radic. Biol. Med. 1996, 20, 933-956. [CrossRef]

70. Olszowy, M. What is responsible for antioxidant properties of polyphenolic compounds from plants? Plant Phys. Biochem. 2019, 144, 135-143. [CrossRef]

71. Cosio, M.S.; Buratti, S.; Mannino, S.; Benedetti, S. Use of an electrochemical method to evaluate the antioxidant activity of herb extracts from the Labiatae family. Food Chem. 2006, 97, 725-731. [CrossRef]

72. Blasco, A.J.; Rogerio, M.C.; González, M.C.; Escarpa, A. “Electrochemical Index" as a screening method to determine "total polyphenolics" in foods: A proposal. Anal. Chim. Acta 2005, 539, 237-244. [CrossRef] 
73. Hoyos-Arbeláez, J.; Vázquez, M.; Contreras-Calderón, J. Electrochemical methods as a tool for determining the antioxidant capacity of food and beverages: A review. Food Chem. 2017, 221, 1371-1381. [CrossRef]

74. Apak, R.; Özyürek, M.; Güçlü, K.; Çapanoğlu, E. Antioxidant activity/capacity measurement. 1. Classification, physicochemical principles, mechanisms, and electron transfer (ET)-based assays. J. Agric. Food Chem. 2016, 64, 997-1027. [CrossRef]

75. Sužnjević, D.Ž.; Pastor, F.T.; Gorjanović, S.Ž. Polarographic study of hydrogen peroxide anodic current and its application to antioxidant activity determination. Talanta 2011, 85, 1398-1403. [CrossRef]

76. Stojićević, A.S.; Pastor, F.T.; Gorjanović, S.Ž.; Šolević Knudsen, T.M.; Antić, M.P. Modification of DC polarographic antioxidant assay-Application to aromatic plants and their active principles. Flavour Fragr. J. 2020, 35, 219-226. [CrossRef]

77. Labuda, J.; Bučková, M.; Heilerová, L.; Čaniová-Žiaková, A.; Brandšteterová, E.; Mattusch, J.; Wennrich, R. Detection of antioxidative activity of plant extracts at the DNA-modified screen-printed electrode. Sensors 2002, 2, 1-10. [CrossRef]

78. De Siqueira Leite, K.C.; Garcia, L.F.; Lobóna, G.S.; Thomaz, D.V.; Moreno, E.K.G.; de Carvalhoa, M.F.; Rocha, M.l.; dos Santos, W.T.P.; Gil, E.S. Antioxidant activity evaluation of dried herbal extracts: An electroanalytical approach. Rev. Bras. Farmacogn. 2018, 28, 325-332. [CrossRef]

79. Flampouria, E.; Sotiropoulou, N.-S.D.; Mavrikou, S.; Mouzaki-Paxinou, A.-C.; Tarantilis, P.A.; Kintzios, S. Conductive polymer-based bioelectrochemical assembly for in vitro cytotoxicity evaluation: Renoprotective assessment of Salvia officinalis against carbon tetrachloride induced nephrotoxicity. BBA Gen. Subj. 2017, 1861, 2304-2314. [CrossRef]

80. Ziyatdinova, G.K.; Ziganshina, E.R.; Cong, P.N.; Budnikov, H.C. Determination of the antioxidant capacity of the micellar extracts of spices in Brij ${ }^{\circledR} 35$ medium by differential pulse voltammetry. J. Anal. Chem. 2016, 71, 573-580. [CrossRef]

81. Filipe, H.A.L.; Sousa, C.; Marquês, J.T.; Vila-Viçosa, D.; de Granada-Flor, A.; Viana, A.S.; Santos, M.S.C.S.; Machuqueiro, M.; de Almeida, R.F.M. Differential targeting of membrane lipid domains by caffeic acid and its ester Derivatives. Free Radic. Biol. Med. 2018, 115, 232-245. [CrossRef] [PubMed]

82. Panya, A.; Kittipongpittaya, K.; Laguerre, M.; Bayrasy, C.; Lecomte, J.; Villeneuve, P.; McClements, D.J.; Decker, E.A. Interactions between $\alpha$-tocopherol and rosmarinic acid and its alky esters in emulsions: Synergistic, additive, or antagonistic effect? J. Agric. Food Chem. 2012, 60, 10320-10330. [CrossRef]

83. Li, Y.; Huang, Q.; Yu, X.; Liu, Y.; Li, L.; Li, B.; Zhang, X.; Chen, S.; Liu, Z.; Zhao, X.; et al. Study of reactions of $\mathrm{N} \varepsilon$-(carboxymethyl) lysine with o-benzoquinones by cyclic voltammetry. Food Chem. 2020, 307, 125554. [CrossRef]

84. Li, Y.; Qi, H.; Fan, M.; Zhu, Z.; Zhan, S.; Li, L.; Li, B.; Zhang, X.; Zhao, X.; Ma, J.; et al. Quantifying the efficiency of o-benzoquinones reaction with amino acids and related nucleophiles by cyclic voltammetry. Food Chem. 2020, 317, 126454. [CrossRef]

85. Zhu, Z.; Zhang, Y.; Wang, J.; Li, X.; Wang, W.; Huang, Z. Sugaring-out assisted liquid-liquid extraction coupled with high performance liquid chromatography-electrochemical detection forthe determination of 17 phenolic compounds in honey. J. Chromatogr. A 2019, 1601, 104-114. [CrossRef]

86. Peng, Y.; Yuan, J.; Liu, F.; Ye, J. Determination of active components in rosemary by capillary electrophoresis with electrochemical detection. J. Pharm. Biomed. Anal. 2005, 39, 431-437. [CrossRef] [PubMed]

87. Zhao, J.; Du, X.; Cheng, N.; Chen, L.; Xue, X.; Zhao, J.; Wu, L.; Cao, W. Identification of monofloral honeys using HPLC-ECD and chemometrics. Food Chem. 2016, 194, 167-174. [CrossRef] [PubMed]

88. Wang, Q.; Zhao, H.; Xue, X.; Liu, C.; He, L.; Cheng, N.; Cao, W. Identification of acacia honey treated with macroporous adsorption resins using HPLC-ECD and chemometrics. Food Chem. 2020, 309, 125656. [CrossRef] [PubMed]

89. Wang, Q.; Zhao, H.; Zhu, M.; Zhang, J.; Cheng, N.; Cao, W. Method for identifying acacia honey adulterated by resin absorption: HPLCECD coupled with chemometrics. LWT 2020, 118, 108863. [CrossRef]

90. Wang, J.; Xue, X.; Du, X.; Cheng, N.; Chen, L.; Zhao, J.; Zheng, J.; Cao, W. Identification of acacia honey adulteration with rape honey using liquid chromatography-electrochemical detection and chemometrics. Food Anal. Methods 2014, 7, 2003-2012. [CrossRef]

91. Chen, X.; Kotani, A.; Hakamata, H.; Wang, J.; Du, S.; Kusu, F. Three-channel column-switching high-performance liquid chromatography with electrochemical detection for determining bioactive redox components in Salvia miltiorrhiza. J. Chromatogr. A 2012, 1256, 105-113. [CrossRef] 
92. Chu, Q.; Tian, X.; Jiang, L.; Ye, J. Application of capillary electrophoresis to study phenolic profiles of honeybee-collected pollen. J. Agric. Food Chem. 2007, 55, 8864-8869. [CrossRef]

93. Peng, L.-Q.; Cao, J.; Du, L.-J.; Zhang, Q.-D.; Shi, Y.-T.; Xu, J.-J. Analysis of phenolic acids by ionic liquid-in-water microemulsion liquid chromatography coupled with ultraviolet and electrochemical detector. J. Chromatogr. A 2017, 1499, 132-139. [CrossRef]

94. Niederlander, H.A.G.; van Beek, T.A.; Bartasiute, A.; Koleva, I.I. Antioxidant activity assays on-line with liquid chromatography. J. Chromatogr. A 2008, 1210, 121-134. [CrossRef]

95. David, I.G.; Popa, D.E.; Buleandra, M. Pencil graphite electrodes: A versatile tool in electroanalysis. J. Anal. Meth. Chem. 2017, 2017, 1-22. [CrossRef]

(C) 2020 by the authors. Licensee MDPI, Basel, Switzerland. This article is an open access article distributed under the terms and conditions of the Creative Commons Attribution (CC BY) license (http://creativecommons.org/licenses/by/4.0/). 